\title{
Zwei markante Stauchmoränen: Peski/Belorussland und Jasmund, Ostseeinsel Rügen/Nordostdeutschland -
} Gemeinsame Merkmale und Unterschiede

Alfred O. Ludwig

Abstract:

\begin{abstract}
Structure, architecture and formation of the push moraine near Peski (Belorussia) are described and compared with those of the push moraine on the Jasmund peninsula (Germany, Rügen Island). It is common to both push moraines, that the Upper Cretaceous and Pleistocene sediments - at Peski Tertiary sands additional - are glacigenously folded and faulted (imbricate structures). The ice rafted folds and slabs in both push moraines resemble to a great extend, while the architectures are fundamentally different. Near Peski an arch-shaped zone of ice pushed ridges had developed at the front of an extensive lobe of the inland ice, but in the Jasmund peninsula region an elevated area must had split the ice stream following the Baltic sea depression into two parts which initially had flown around the elevation and the first pushed ridges. Therefore the glacigenic compression at Jasmund has started from the flanks of two ice tongues. The interpretation as an acute notched push moraine („Kerbstauchmoräne") is compared with the idea of a firstly loop-shaped installed zone of ice pushed ridges, which have been reshaped by the ice later on. Furthermore the geological position of both push moraines is discussed in relation to the fault structures below the Quaternary cover as well as to the tectonic reactivations of these faults up to the Pleistocene period.

The glacigenous deformation near Peski is ascribed to the Sosch-(Warthe-)ice advance, but the formation of the Jasmund push moraine is classified as a Weichselian event (post Brandenburg phase). Characteristic of both events is that they followed a glaciation's climax after the maximum ice sheet propagation. Obviously these declining climatic periods had provided exceptional soil physical conditions for the ice effects on the underground.
\end{abstract}

[Two striking push moraines: Peski/Belorussland and Jasmund/Rügen Island,NE Germany - common features and differences]

Kurzfassung

Strukturen, Architektur und Genese der Stauchmoräne Peski/ Belorussland werden beschrieben und mit der Stauchmoräne Jasmund/Rügen verglichen. In beiden Stauchmoränen sind Oberkreide- und Pleistozänfolgen, bei Peski zusätzlich tertiäre Sande, glazigen gefaltet und verschuppt worden. Die Falten und Schuppen gleichen sich in beiden Stauchzonen in den Formen und Ausmaßen weitgehend. In ihrer Architektur unterscheiden sich beide Großstrukturen jedoch prinzipiell voneinander: Bei Peski ist eine bogenförmige Stauchzone an der Stirn eines ausgedehnten Eislobus entstanden; auf Jasmund ist der Eisstrom, der der Ostseesenke gefolgt war, durch ein höher liegendes Areal zweigeteilt worden und hat dieses samt den ersten Stauchwällen zunächst umflossen. Hier ist die Stauchung von den Flanken zweier Eiszungen ausgegangen. Der Interpretation als einer spitzwinkligen Kerbstauchung wird die Vorstellung einer in der Anlage schlingenförmig gerafften Stauchung gegenübergestellt, die später vom Eis überprägt worden ist. Die Lagebeziehungen beider Stauchmoränen zu den Bruchstrukturen im präquartären Untergrund der Region und zu deren neotektonischen Mobilität werden diskutiert.

Die glazigene Stauchung bei Peski wird dem Sosch-(Warthe-)eis zugeschrieben, die auf Jasmund der Weichselvereisung. Beide Stauchungen sind nach dem Höhepunkt einer Vereisung, nach der maximalen Eisausbreitung, erfolgt. Diese rückläufigen Kälteperioden boten besonders günstige Voraussetzungen für Einwirkungen des Inlandeises auf den Untergrund.

Keywords:

push moraine, structural elements, formation, Pleistocene, Belorussia, NE Germany

Address of author:

A.O. Ludwig, Auf dem Kiewitt 12/79, D-14471, Potsdam.

\section{Einleitung}

In die Stauchmoräne bei Peski im Westen Belorusslands sind Oberkreideschichten in die glazigene Deformation einbezogen, ähnlich wie in der Stauchmoräne Jasmund/ Insel Rügen. Der Vergleich beider Stauchmoränen soll die gemeinsamen Merkmale und Unterschiede aufzeigen und glazialgeologisch auswerten. Prof. Dr. E. A. Levkov†, Institut für Geologische Wissenschaften der Akademie der Wissenschaften Belorusslands in Minsk, hat den Bau der Stauchmoräne Peski mit ihren umfangreichen Lagerstätten an Oberkreidekalk (in Schreibkreidefazies mit Flint) in jahrelanger Erkundungsarbeit für die Zementindustrie weitgehend geklärt (LEvKov 1980 und mündliche Mitteilung 1996 vor Ort). Der folgende Überblick basiert auf den Ergebnissen von Levkov.

\section{Die Stauchmoräne bei Peski, Gebiet Grodno, Westbelorussland}

\subsection{Allgemeines und Architektur der Stauchmoräne Peski}

Die Stauchmoräne liegt in Luftlinie ca. $700 \mathrm{~km}$ von Jasmund entfernt und ca. einen Breitengrad südlicher (Abb. 1, 2). Ihre flachen, parallelen Hügelketten erheben sich um 15-20 m über das nach SE flach ansteigende und sie umgebende Tiefland (ähnliche Stauchmoränen Belorusslands erheben sich auch nur um 20-30 m über ihre Umgebung). Die Hügelketten bilden einen ca. $25 \mathrm{~km}$ langen Stauchmoränenbogen, der dem Sosch-(Warthe-)Eisvorstoß zugeschrieben wird und von diesem noch überfahren worden ist. Die Einzelstrukturen werden von der Sosch-Moräne (u.a. flow 


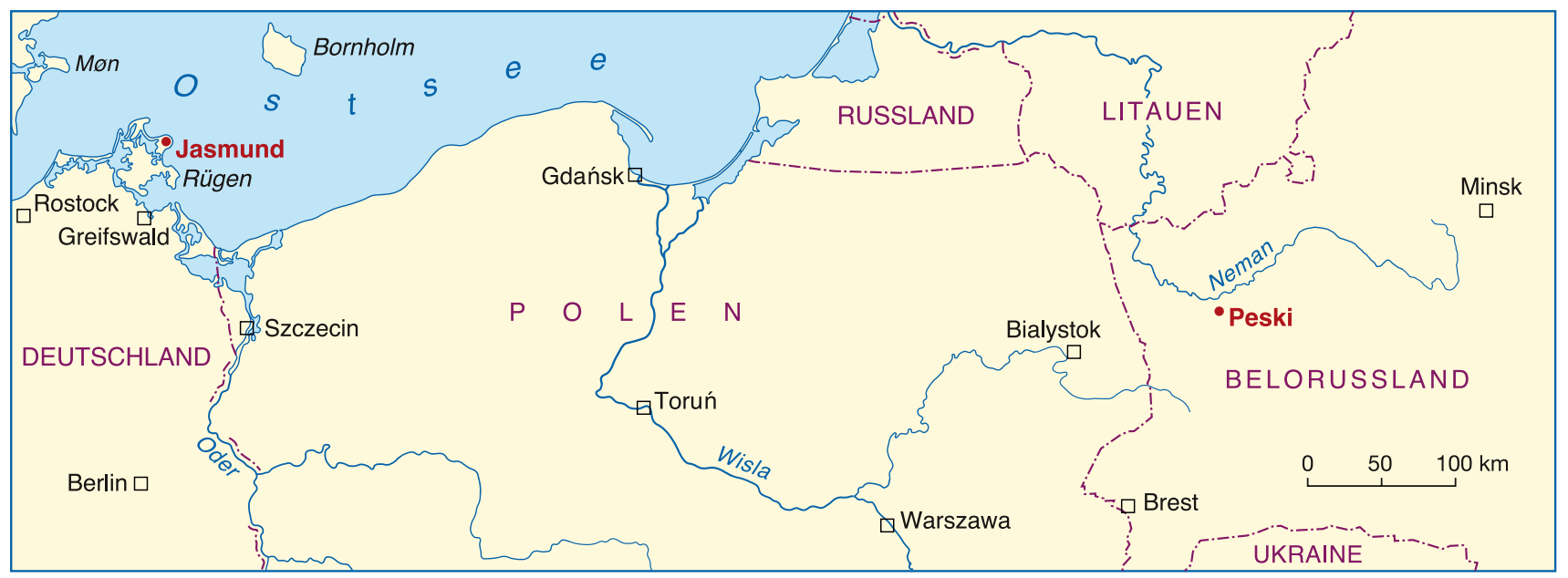

Abb. 1: Lage der Stauchmoränen Peski und Jasmund.

Fig. 1: Locations of Peski and Jasmund push moraines.

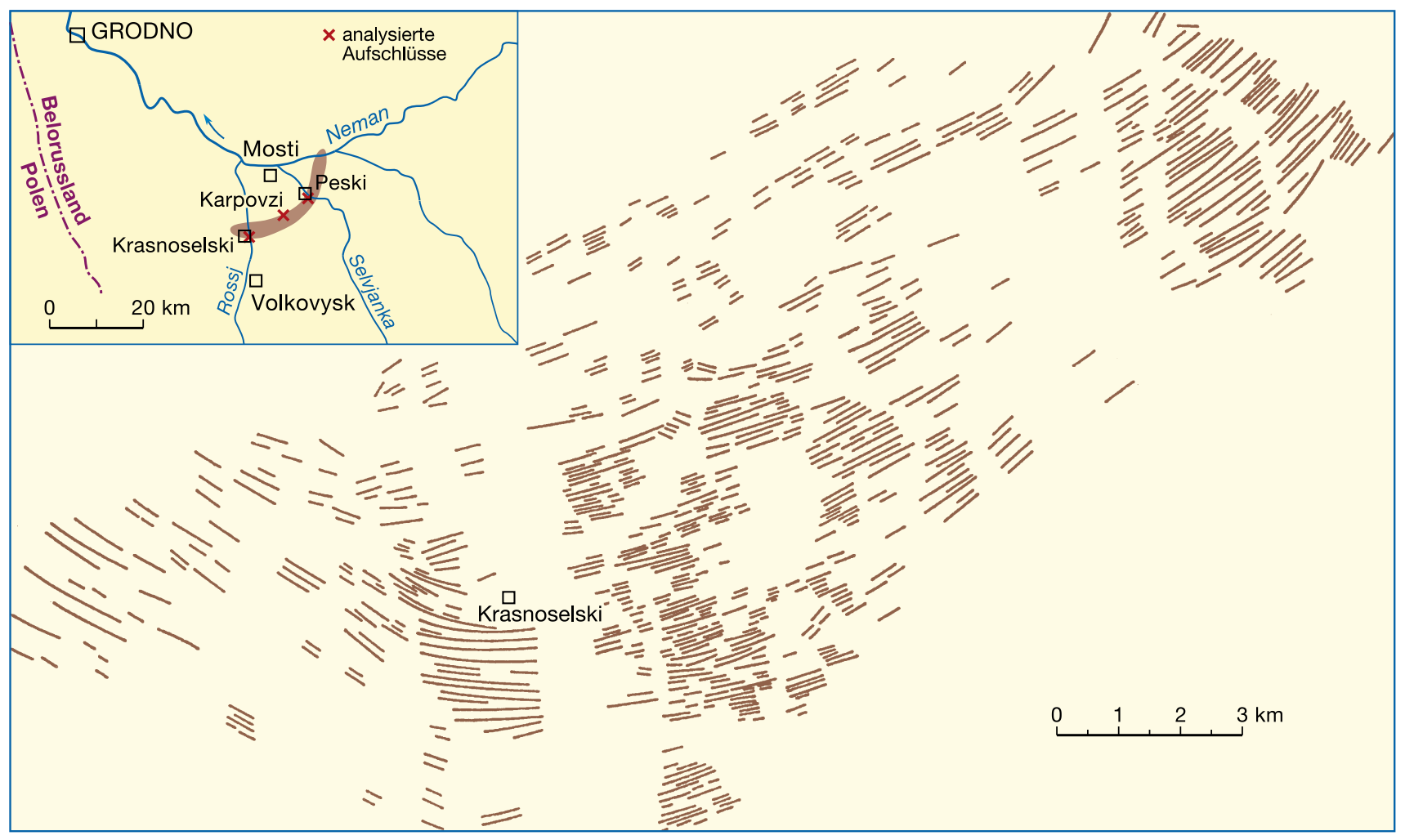

Abb. 2: Grundriss des Falten- und Schuppenbaus der Stauchmoräne Peski, Rayon Grodno (nach LEVKov 1980); links oben Lage der behandelten Aufschlüsse. Dargestellter Stauchmoränenbogen ca. $25 \mathrm{~km}$.

Fig. 2: Folds and imbricate structures of the push moraine Peski in plan, Grodno region (from LEVKOV 1980); inset: locations of the studied exposures of the Peski push moraine. Outlined ice pushed lobe about $25 \mathrm{~km}$.

till) und fluvioglazialen Sedimenten diskordant überdeckt. Der Außenrand des Sosch-Eises lag ca. $80 \mathrm{~km}$ südlich bis südwestlich der Stauchmoräne. Diese ist an einigen Stellen in bis $\mathrm{zu} 4 \mathrm{~km}$ langen und bis $40 \mathrm{~m}$ tiefen Gruben für die Kreidegewinnung (Zementindustrie) gut aufgeschlossen. Die Gruben folgen dem Streichen der Stauchungsstrukturen (Abb. 2).

Von der Stauchung betroffen ist eine Schichtfolge von Oberkreide des Campan mit Lagen von Flintknollen, von Sanden des Obereozän, sandig-tonigen Sedimenten des
Neogen (Miozän?) und Ablagerungen des Pleistozän (Abb. 3). Fossilführende Sedimente interstadialer und interglazialer Perioden sind nicht beobachtet worden.

\subsection{Innerer Bau [Strukturelemente] und Genese der Stauchmoräne Peski}

In dem 3-5 km, maximal $8 \mathrm{~km}$ breiten Stauchungsbogen folgen bis zu 20 größere Falten- und Schuppenstrukturen quer zum Streichen aufeinander (anderenorts in Belorussland bis 


\section{Peski/Belorussland}

Präpleistozän nach LEVkov 1980, Pleistozän: Aufnahme A. O. LUDWIG im Aufschluss Karpovzi, 1986, 1996, siehe Abb. 8a
Jasmund/Ostseeinsel Rügen/BRD

nach A. O. LuDWIG 2006, Abb. 2, vereinfacht

\begin{tabular}{|c|c|}
\hline & Geschiebemergel Sosch-(Warthe-) \\
\hline & warthezeitlich \\
\hline & Schluff, gefältelt \\
\hline & Lagen mit Rippelschichtung in Feinsand \\
\hline & Sand mit Schlufflagen \\
\hline 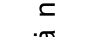 & \\
\hline 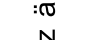 & Bänderton \\
\hline $\begin{array}{l}N \\
0\end{array}$ & heller Sand \\
\hline$\vec{\omega}$ & \\
\hline$\overline{0}$ & Geschiebemergel mit Sandlinsen \\
\hline & glazifluvialer Sand und Kies \\
\hline & Geschiebemergel mit Geröllauflage \\
\hline & glazifluvialer Vorschüttsand \\
\hline \begin{tabular}{l}
\multicolumn{1}{c}{} \\
0 \\
0 \\
0 \\
0 \\
0 \\
$Z$
\end{tabular} & $\begin{array}{l}\text { bräunliche und gelblich-weiße Quarzsande, } \\
\text { gelbe bis bräunliche Tone } \\
\text { ? Miozän }\end{array}$ \\
\hline $\begin{array}{l}\text { Paläo- } \\
\text { gen }\end{array}$ & $\begin{array}{l}\text { glaukonitischer toniger Feinsand mit } \\
\text { Foraminiferen des Obereozän, Lage } \\
\text { phosphoritisch zementierter Sandknollen }\end{array}$ \\
\hline Ober- & $\begin{array}{l}\text { Schreibkreide mit wenigen Lagen von } \\
\text { Flintknollen, ungestört }\end{array}$ \\
\hline & in der Region \\
\hline
\end{tabular}

Campan

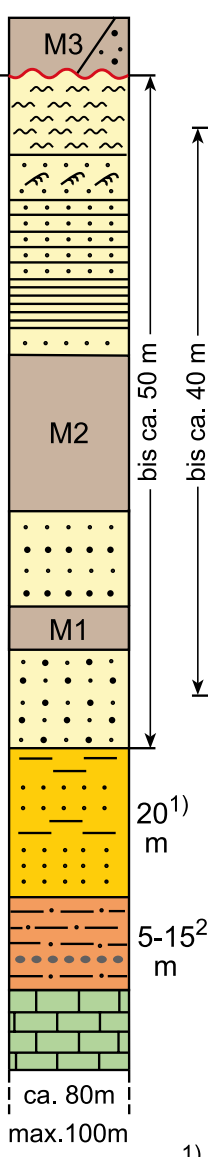

$5-15^{2)}$

$\sim$ Hauptdiskordanz

$\sim$ schwächere Diskordanz

Mächtigkeiten nicht genau maßstäblich

1) primär, in den Schuppen $10-15 \mathrm{~m}$

2) primär, annähernd gleich in den Schuppen

Abb. 3: Die stratigraphischen Normalprofile der glazigen gestörten Schichtfolgen bei Peski / Belorussland und auf der Halbinsel fasmund / Rügen.

Fig. 3: The stratigraphic sequences, glacigenous dislocated near Peski / Belorussia and on fasmund peninsula / Rügen.

zu 22, in der Ukraine bis zu 35, mündliche Mitteilung von Levkov). Das abgescherte und gefaltete beziehungsweise verschuppte Schichtpaket ist etwa auf die Hälfte seiner ursprünglichen Länge verkürzt worden. Für die Stauchmoräne Muskauer Faltenbogen (s. unten) gibt KuPETz (1997) nach Rückrotation der Schuppen ebenfalls ca. 50\% Verkürzung an. Als Strukturelemente kommen vor: stehende isoklinale Falten, Schleppfalten, Kofferfalten, Faltenüberschiebungen bis zu dachziegelartig gelagerten Schuppenstrukturen. Stellenweise, vor allem im Bereich von glazigenen Querstörungen (s. u.), treten wesentlich kompliziertere, schwer $\mathrm{zu}$ erfassende und zu deutende Strukturformen auf. Injektivfalten waren in der Stauchmoräne Peski nicht aufgeschlossen. Anderenorts sind in Belorussland Injektivfalten mit Amplituden von 50 bis zu $90 \mathrm{~m}$ beobachtet worden (mdl. Mitt. Levkov).

Die Vergenz der Falten- und Schuppenstrukturen ist vom Eis weggewandt, selten umgekehrt. Die Neigung der Schuppen steigert sich in der Regel von $30^{\circ}-40^{\circ}$ auf der $\mathrm{Au}-$ ßenseite des Stauchungsgürtels bis auf $90^{\circ}$ auf der Innenseite, mit Einfallen in nordwestliche Richtungen, dem Eis zugewandt. Dementsprechend ändert sich die Ausstrichbreite im Kartenbild von 80-100 m innen auf 200-230 m außen. In der Regel befinden sich die Schichten auf dem Hangendflügel der Strukturen in ihrem ursprünglichen Verband. Das abgescherte und gestauchte Schichtpaket ist bis $\mathrm{zu} 80 \mathrm{~m}$, bisweilen $160 \mathrm{~m}$ über seine ursprüngliche Lage gehoben worden (Abb. 4 u. 5).

Als bemerkenswert erscheint es, dass unter der Basis des obereozänen Sandes auf der Kreide ungeachtet der beträchtlichen Lücke (Maastricht bis einschließlich Mitteleozän fehlen) weder eine Bodenbildung noch eine Anreicherung von Flintknollen noch Verkarstungserscheinungen noch sonstige Merkmale einer Sedimentationsunterbrechung zu beobachten waren. Die in der Kreide heute sichtbaren bis 4,5 m langen Karströhren (Geologische Orgeln) stehen ähnlich wie auf Jasmund vertikal in der Kreide, unabhängig von deren Lagerung (Abb. 6a, b). Sie sind durch die Stauchung nicht verstellt worden sondern erst nach der Stauchung unter der dünnen diskordanten Pleistozänauflage entstanden.

\subsection{Aufschlussbeispiele}

Einige Aufschlussbilder sollen helfen, die Darstellung zu veranschaulichen: In einer Kreidegrube bei Krasnoselski 


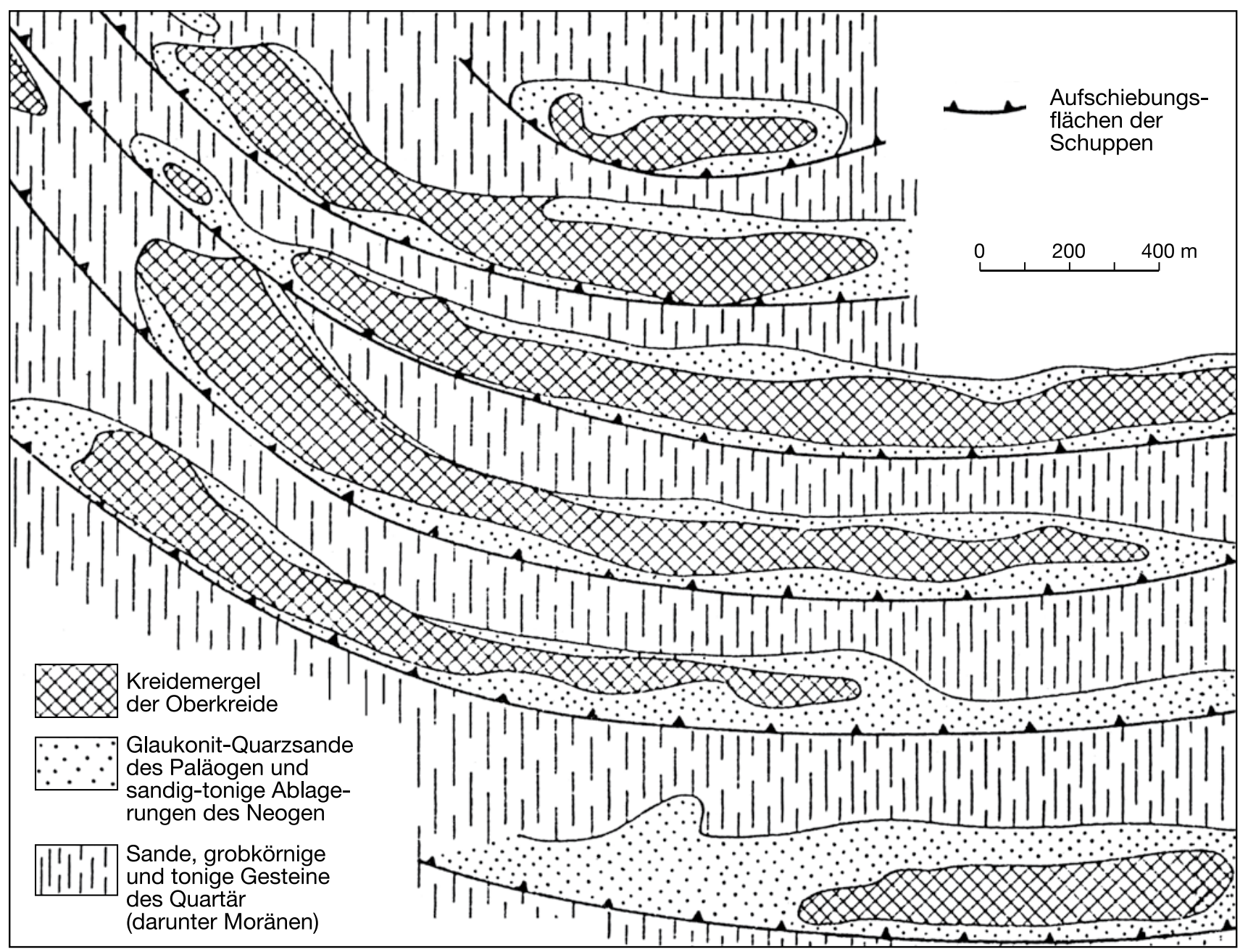

Abb. 4: Geologisches Kartenbild bei Krasnoselski, Südteil der Stauchmoräne Peski, ohne diskordant auflagerndes Pleistozän (aus LEVKov 1980). Fig. 4: Geological map, area near Krasnoselski, southern part of the Peski push moraine, without discordant Pleistocene beds (from LEVKOV 1980).

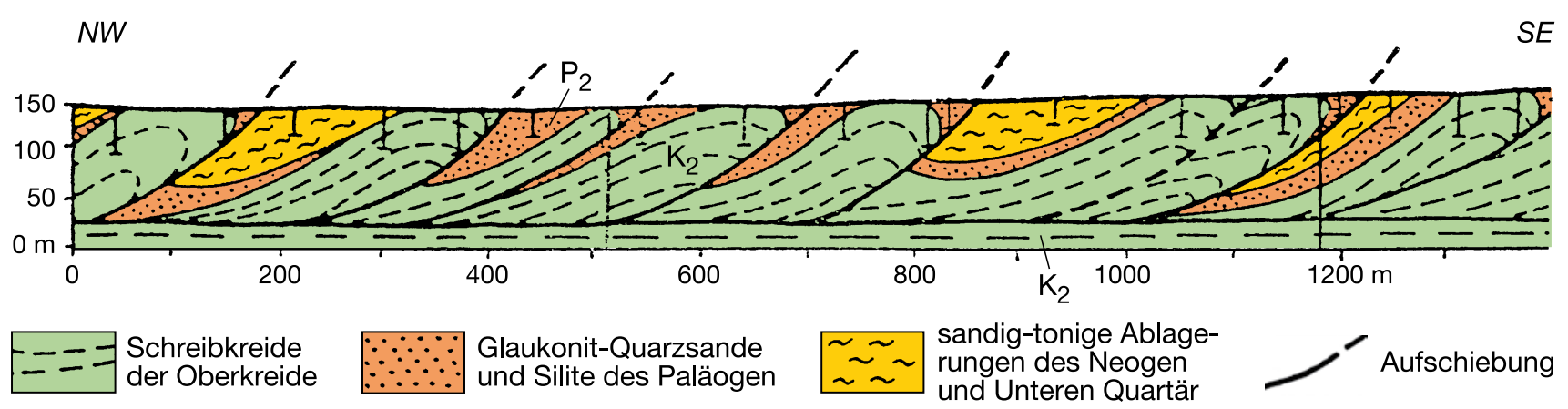

Abb. 5: Geologischer Schuppenbau (Querprofil) der Stauchmoräne Peski (aus LEVKOV 1980).

Fig. 5: Geological structure (transverse section) of the Peski push moraine (from LEVKOV 1980).

(Abb. 2) ist eine breite Kofferfalte angeschnitten. Im Zwickel vor ihrer Stirn zur im Süden folgenden Struktur sind Sande des Paläogen und Neogen fächerförmig steil eingequetscht, mehr oder weniger parallel zu den abtauchenden Flintbändern in der Kreide (Abb. 6a, b). Auf der flacher einfallenden Nordseite ist nur das Paläogen noch über der Kreide angeschnitten. Der diskordante Geschiebemergel ist technisch abgeräumt.

Die südliche Grube bei Karpovzi (Abb. 2) lieferte ein Beispiel für kompliziertere glazigene Deformationen: die Ein- spießung eines Kreidekeils in die hangenden Obereozänsande auf dem Hangendflügel einer Kreideschuppe (Abb. 7). Außerdem durchziehen stellenweise Schnüre dieser Sande die Kreide, und in einer gelbgrauen Schmierzone haben sich die Kreide und die Obereozänsande miteinander vermischt. Schwieriger ist die Deutung der Lagerungsformen zwischen den Kreideschuppen im Detail, da die Kontaktzonen zwischen diesen, für die Kreidegewinnung weniger interessant, in der Regel nicht aufgeschlossen werden. So war es ein Glücksfall, 1986 beim Ort Karpovzi (Abb. 2) ei- 
(a) $s$
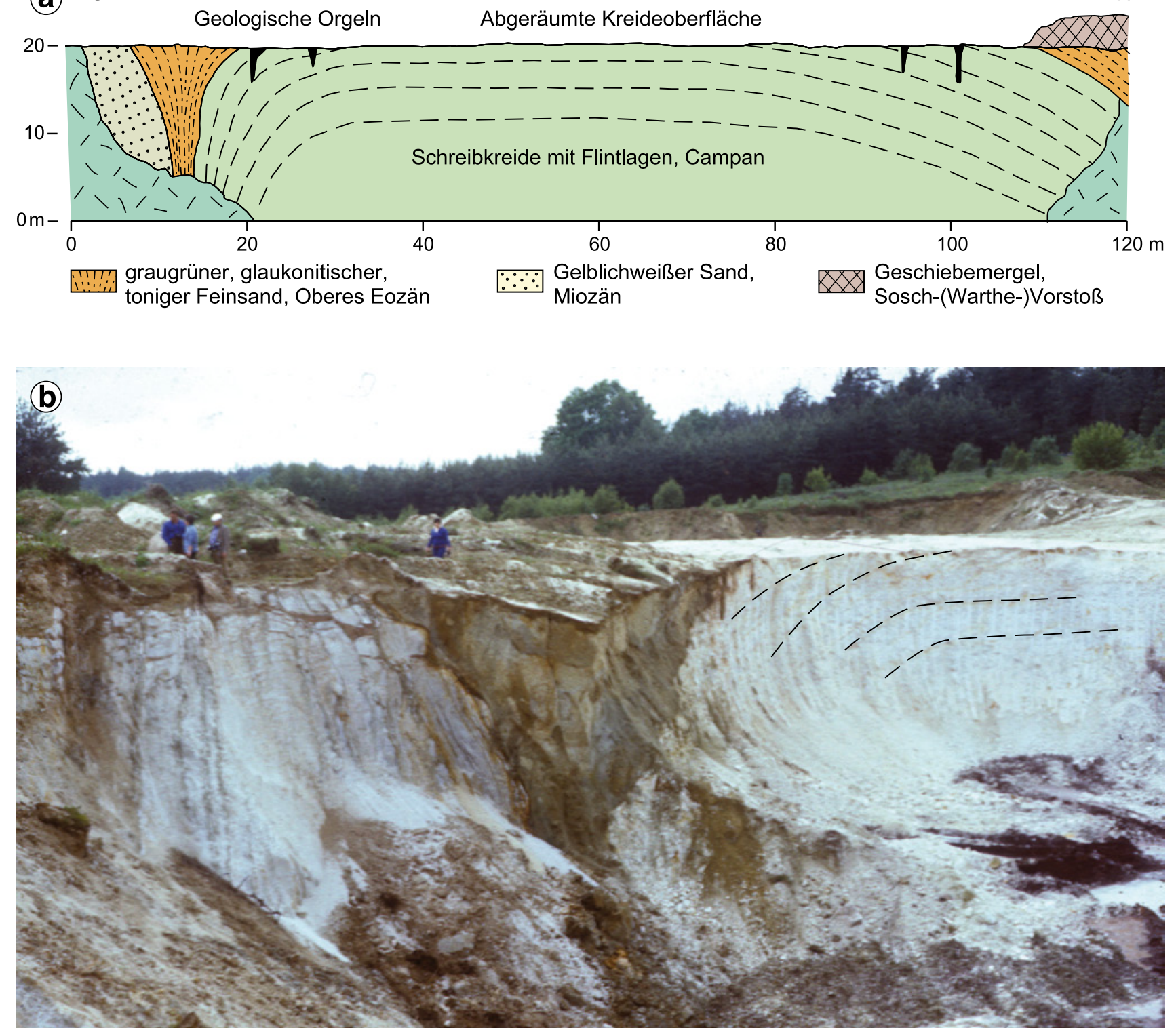

Abb. 6a: Kofferfalte, Kreidegrube bei Krasnoselski (Aufnahme: A. O. LUDWIG 1986).

Abb. 6b: Steil gestellte paläogene und neogene (hell) Sande vor der Stirn der Kofferfalte der Abb. 6a, Kreidegrube bei Krasnoselski (Foto: A. O. LuDWIG 1986).

Fig. 6a: Coffer fold, chalk pit near Krasnoselski (sketched: A. O. LUDWIG 1986).

Fig. 6b: Steeply set up Paleogene and Neogene (light) sand beds in front of the coffer fold presented in fig. 6a, chalk pit near Krasnoselski (photo: A. O. LUDWIG 1986).

nen frischen Anschnitt quer zum Streichen zwischen zwei Falten-(Schuppen-)strukturen dokumentieren zu können (Abb. 8 a, b). Das seltene Profil gibt Einblick in den Deformationsmechanismus, der sonst weitgehend aus Bohrprofilen abgeleitet werden musste.

Das Querprofil zeigt im Norden und Süden steil aufgerichtete Schichten (Oberkreide bis erster Geschiebemergel der Pleistozänfolge) und in der Mitte Muldenstellung der höheren Glieder des Pleistozäns. Südlich des Muldenzentrums hatte sich eine Mobilzone entwickelt in der Schichten unterdrückt beziehungsweise in ihrer Mächtigkeit reduziert worden sind. Das trifft zu auf den fluvioglazialen Sand zwischen den Geschiebemergeln I und II, den Geschiebemergel II und den Sand mit Schlufflagen zwischen Meter 50 und 60. In der Mobilzone sind die Schichten stark verpresst und mehr oder weniger vermischt worden, vor allem der
Bänderton und Teile des hangenden Sandes mit Schlufflagen, die bei der Deformation als Schmiermittel gewirkt haben. Anscheinend sind auch Anteile vom Geschiebemergel II darin enthalten. Die starke Kompression im Inneren der Mulde hat diese leicht beweglichen Sedimente auf dem Südflügel vor allem nach oben ausgequetscht, während andere Schichten und Schichtteile in der Tiefe verblieben sind. Offen bleibt, ob diese Quetschzone nur auf den jüngeren Teil der Pleistozänfolge, der sich eng an das Muldenzentrum anschließt, beschränkt ist - ähnliche Deformationsbilder sind aus Norddeutschland bekannt - oder, ob die mobile Zone Teil einer tiefergreifenden eistektonischen Störzone im Kontaktbereich zwischen zwei Falten oder Schuppen ist. Der in anderen Aufschlüssen der Stauchmoräne Peski beobachtete diskordante Geschiebemergel des Sosch-Eisvorstoßes fehlt hier. Nur grobe glazifluviale Sedi- 


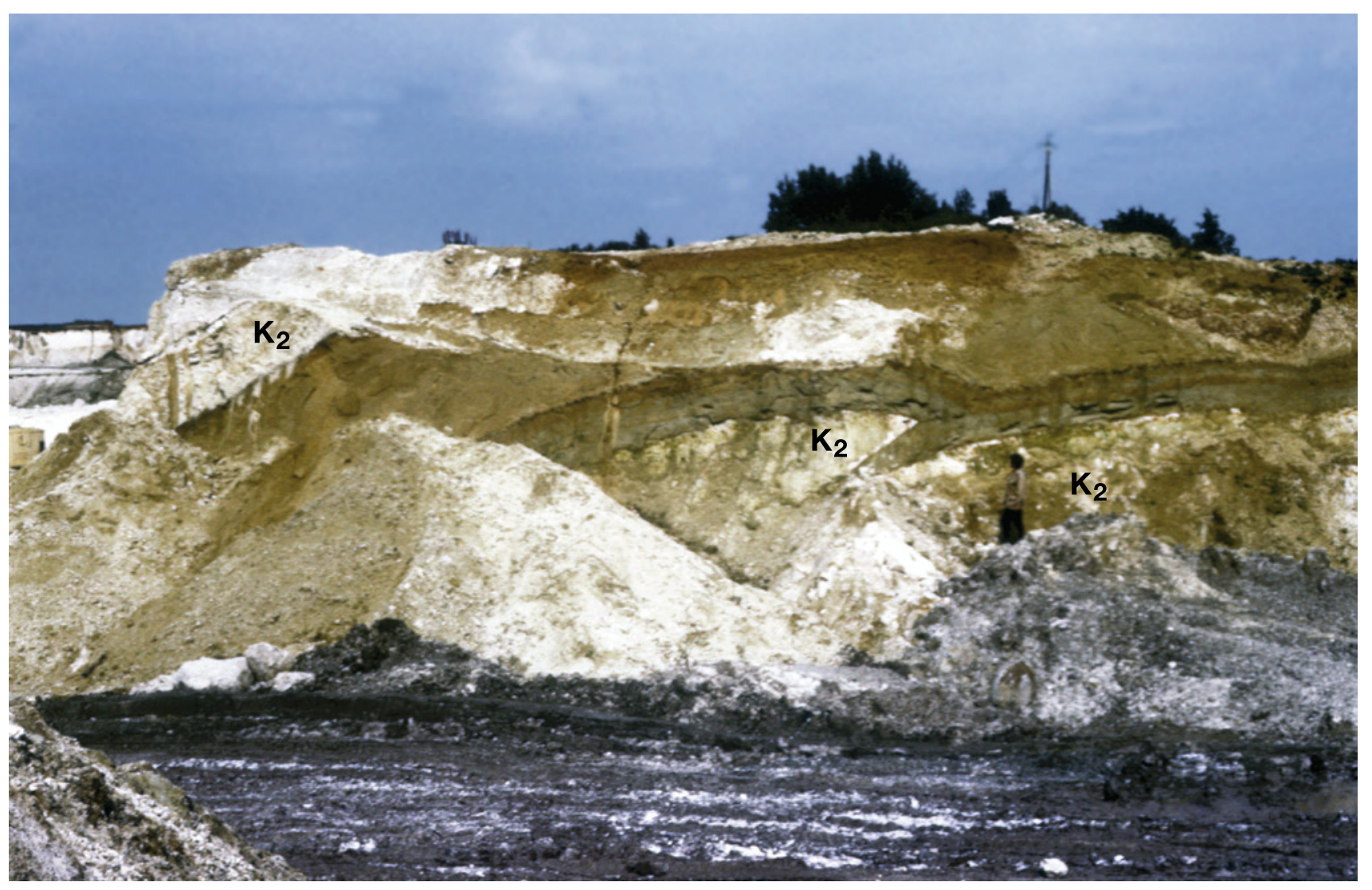

Abb. 7: Komplizierte glazigene Deformation von Kreide-Paläogen-Schichten in einer Kreidegrube bei Karpovzi (Foto: A. O. LuDWIG 1986).

Fig. 7: More complicated glacigenous deformation of chalk and Paleogene beds in a chalk pit near Karpovzi (photo: A. O. LUDWIG 1986).

mente schließen in erosiv diskordanter Auflage das Profil zum Hangenden hin ab. Das stauchende Eis hat keine lückenlose Geschiebemergeldecke hinterlassen.

\subsection{Architektur und Genese der Stauchmoräne Peski}

Die Architektur der Stauchmoräne ist sehr regelmäßig, geradezu lehrbuchmäßig gestaltet. Es liegt ein Dehnungsbogen vor, gebildet an der Stirn eines großen Gletscherlobus (Abb. 2 u. 9). Im Landschaftsbild hebt sich der Stauchmoränenbogen noch durch flache parallele Rücken hervor, die 15-20 m über die Umgebung aufragen. Mit der Vergrößerung seines Radius bei der Stauchung war notwendig eine Weitung des Bogens (eisauswärts konvexer Dehnungsbogen) verbunden. Diese Dehnungen sind durch Querstreckung der beim Zusammenschub unter Kompression stehenden Schichten kompensiert worden, sodass quer zum Streichen keine Lücken aufgerissen sind. Gleichzeitig ist beim Zusammen- und Vorschub durch das andringende Eis Material nach oben, in Richtung des geringsten Widerstands, ausgequetscht und sind die Falten und Schuppen zunehmend steiler aufgerichtet worden, auf der Innenseite des Bogens stärker als außen.

Andererseits hat das Eis benachbarte Abschnitte der vom Untergrund abgescherten Schichtfolge unterschiedlich stark zusammengeschoben, abhängig von den materiellen Inhomogenitäten im Eis und daraus folgenden Bewegungsinhomogenitäten (innere Reibung und Bodenreibung) und von den topographischen, bodenmechanischen und klimatischen Parametern in seinem Vor- und Umfeld.
Folge des ungleichmäßig starken Zusammenschubs benachbarter Bogenabschnitte zusammen mit der Weitung des Bogens ist eine Quergliederung des Stauchungsbogens durch Querstörungen mit seitlichen Versätzen an den Grenzen benachbarter Sektoren. Diese Versätze sind als horizontale Flexuren oder Rupturen (Scherungszonen) ausgebildet (Abb. 9). Dabei wird das radiale Spaltensystem des Gletscherlobus bis zu einem gewissen Grade in den Stauchungsgürtel vor der Gletscherstirn übertragen. Außerdem kommen kompliziertere, schwer zu erfassende und zu deutende Deformationen vor. Die Querstrukturen bilden Schwächezonen. Das in diesen aufgelockerte Gesteinsgefüge widersteht der fluviatilen Ausräumung weniger. Ausgeprägteren Schwächezonen folgen die Flüsse Selvjanka und Rossj (Abb. 2 u. 9). Die Querversätze, an denen die Falten- und Schuppenstrukturen abreißen, haben die Länge der Kreidegruben im Streichen der Schichten bestimmt. Im Dehnungsbogen der Stauchmoräne Peski messen die Kreidegruben in der Regel um 2, maximal 4 km. Im Muskauer Faltenbogen (ohne Kreideanteile, s. u.) sind die Schuppenstrukturen auf ähnliche Erstreckungen zu verfolgen (KupETz 1997).

Im Hinterland jeder derartigen Stauchmoräne in Belorussland findet sich eine Geländedepression, die das Areal bezeichnet, aus dem die gestauchten Schichtpakete herzuleiten sind.

Ein in den Ausmaßen vergleichbares Objekt ist die sehr gut untersuchte Stauchmoräne Muskauer Faltenbogen (im engeren Sinne) südöstlich von Cottbus (KuPETz 1997). Sie bildet den äußersten (südlichsten) und jüngsten einer Staf- 


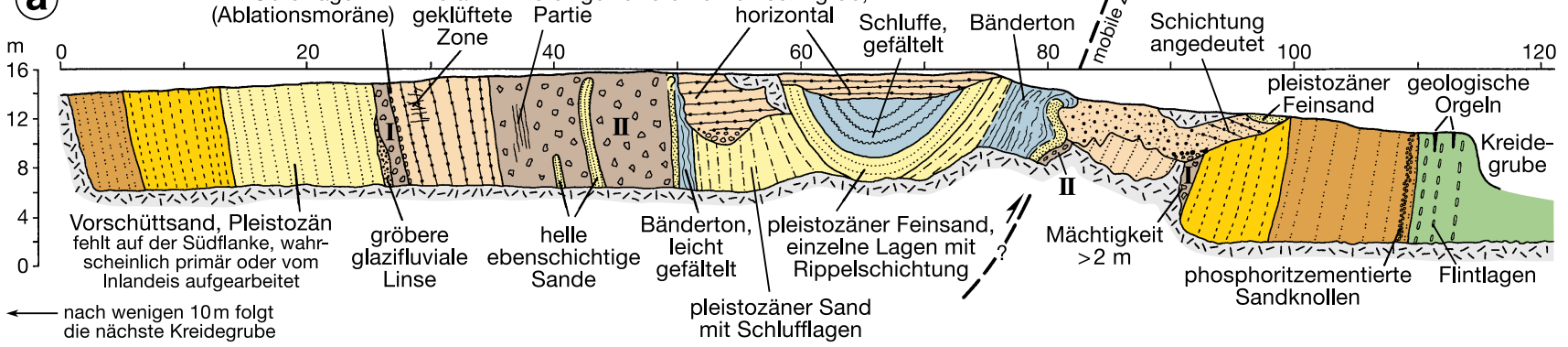
die nächste Kreidegrube mit Schlufflagen

F-s Schreibkreide mit Flintlagen, Oberkreide

Feinsand, glaukonitisch, Obereozän
Eeller Feinsand und Ton, Neogen
9.: glazifluvialer Sand und Kies, geschichtet/ohne erkennbare Schichtung

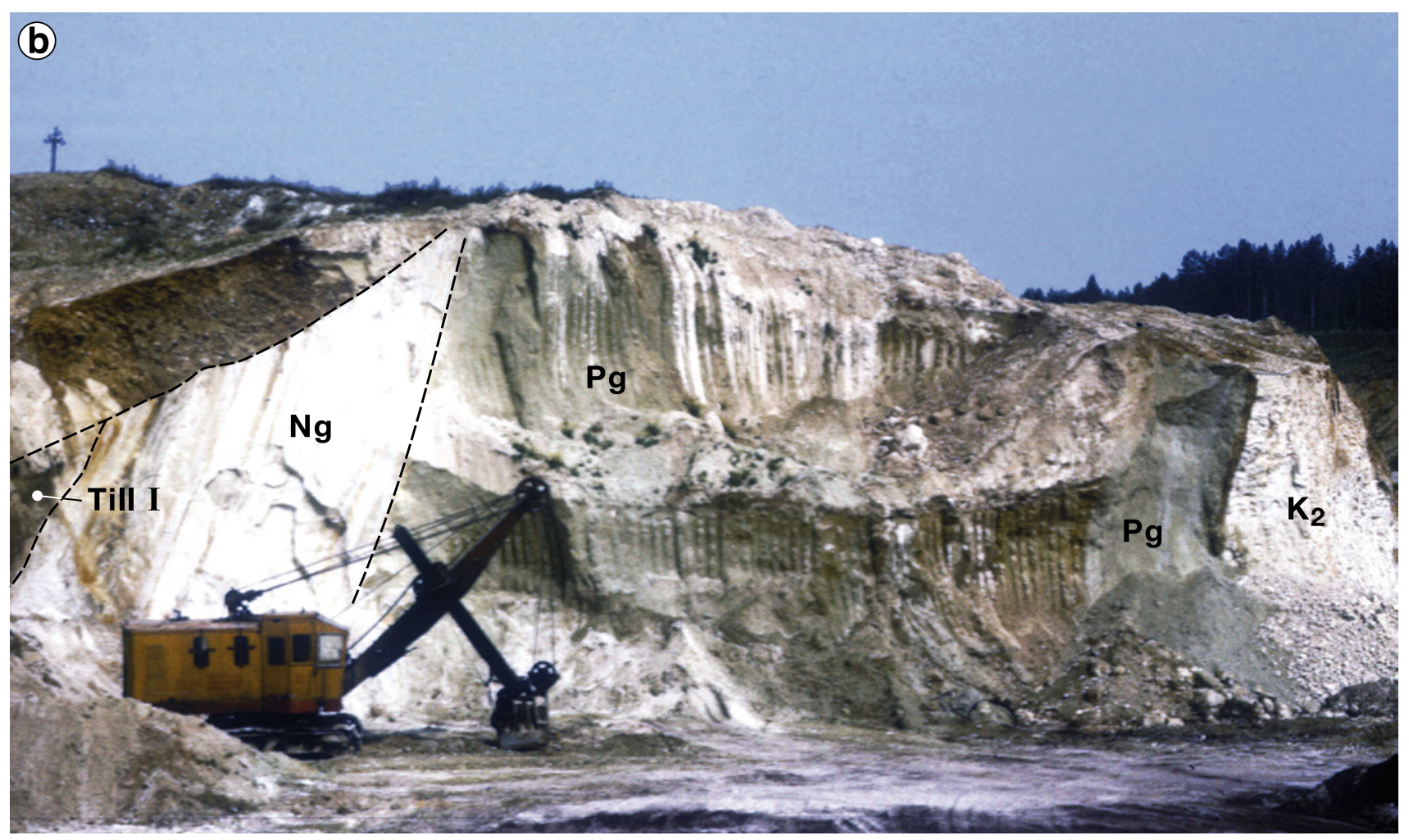

Abb. 8a: Geologisches Querprofil durch die Pleistozän- und Tertiärfolge zwischen zwei Kreidestrukturen bei Karpovzi (geologische Aufnahme: A. O. LUDWIG 1986).

Abb. 8b: Steil gestellte Kreide-Tertiär-Schichten und Geschiebemergel I unter diskordant aufgelagertem fluvioglazialem Sand und Kies; Südteil des Profils der Abb. 8a; Karpovzi, K2 - Oberkreide, Pg - Paläogen, Ng - Neogen (Foto: A. O. LuDWIG 1986).

Fig. 8a: Geological profile crossing the Pleistocene and Tertiary sequences between two chalk structures near Karpovzi (geological sketch: A. O. LuDwIG 1986). Fig. 8b: Steep set up Cretaceous-Tertiary beds and till I discordant superimposed by Pleistocene sand and gravel; southern part of profile fig. 8a; Karpovzi, K2 - Upper Cretaceous chalk, Pg - Paleogene, Ng - Neogene (photo: A. O. LuDWIG 1986).

fel von drei hintereinander liegenden Stauchmoränenbögen. Diese sind während zunehmend nach $S$ ausgreifender Vorstoßetappen des Elster-II-Eises entstanden. Das Eis folgte auch hier einer flach nach $S$ schwach ansteigenden Hohlform des Geländes. Der Muskauer Faltenbogen zeigt ebenfalls die Architektur und Merkmale eines Dehnungsbogens mit Weitungen quer zum Streichen der Strukturen. An diesen sind die Schichten bis zu $100 \mathrm{~m}$ gegeneinander versetzt. Den Stauchungsbogen durchbricht die Neiße in nördlicher Richtung.
Das strukturelle Inventar ist in den Formen und Dimensionen dem in der Stauchmoräne Peski ähnlich, desgleichen die Verkürzung auf ca. 50\% der ursprünglichen Länge und die Tiefenlage der Abscherzone im Untergrund. Einzelne Schuppenstrukturen halten im Streichen bis zu 3 km Länge und mehr aus. Im Unterschied zur Stauchmoräne Peski sind im Muskauer Faltenbogen weniger feste feinklastische Sedimente und Braunkohleflöze deformiert worden, Schreibkreide fehlt. Demgemäß treten plastisch-fließende Verformungen (Falten), besonders auf der Innenseite des 
Faltenbogens, stärker hervor als rupturelle (Schuppen). Erstere sind nach KupETz (1997) unter dem randlichen Eis entstanden, letztere vor der Stirn des Eislobus. Die eisnahen Schuppen sind ebenfalls steiler gelagert als die eisferneren.

Überliefert ist im Muskauer Faltenbogen nur der stark gekappte Rest der Stauchmoräne. Außer den Eisübergängen (Elster- und Saale-Eis) haben Erosion und Verwitterung während der späteren Wärme- und Kälteperioden das Stauchmoränenrelief weitgehend eingeebnet.

\section{Die Stauchmoräne Jasmund}

\subsection{Allgemeines}

Die Stauchmoräne Jasmund ist kleiner dimensioniert als die Stauchmoräne Peski, jedoch nehmen ihre Strukturelemente mit mehreren $10 \mathrm{~m}$ bis $>100 \mathrm{~m}$ ähnliche Ausmaße ein. Auch die Strukturformen beider Stauchmoränen gleichen sich weitgehend (Abb. 10 u. 11). Aufgeschlossen ist die Stauchmoräne Jasmund weniger gut als die Stauchmoräne Peski, jedoch sind einige Erkundungsfelder, vor allem im Südteil von Jasmund und im Norden, beim Ort Gummanz, von GRотн für die Kreideindustrie näher untersucht worden. Seine Ergebnisse haben die Kenntnisse über den Bau in diesen Teilen der Stauchmoräne bedeutend erweitert und die strukturelle Interpretation sehr gefördert (GROTH 1961, 2003). Die gestauchte Schichtfolge zeigt Abb. 3.

Für die erkundeten Gebiete ist ein relativ regelmäßiger Schuppenbau mit im Süden W- und im Norden SW-Vergenzen ermittelt worden und mit bis zu 15 Kreideschuppen hintereinander. Im Nordflügel, bei Gummanz, erstreckt sich mit 1500 m die im Streichen längste erkundete Kreideschuppe (GRотн 2003). Der größte industrielle Aufschluss, der Kreidetagebau Wittenfelde, liegt am Rande der Kernzone der Stauchmoräne (Hochjasmund).

Im unter Naturschutz gestellten Kernteil der Stauchmoräne (ca. $4 \mathrm{~km} \mathrm{~N}$-S- und ca. $5 \mathrm{~km} \mathrm{E-W-Erstreckung)} \mathrm{gibt}$ es sehr wenige Aufschlüsse, nur alte, kleine Kreidegruben. Die wenigen Streich- und Fallwerte von dort zeigen ein unregelmäßigeres Bild, wie das für diesen Teil, der unter der stärksten Kompression und Quetschung gestanden hat, nicht anders zu erwarten ist. Nur das Kreidekliff an der Ostküste von Jasmund schließt die Kernzone auf, jedoch im ungünstigen, sehr spitzwinkligen Anschnitt der glazigenen Strukturen (s. Ludwig 1954/55: Abb. 9). Südlich der Kernzone der Stauchmoräne sind vor allem Schuppenstrukturen mit mehr oder weniger steil stehenden W-vergenten und nach SE fallenden Schichten ausgebildet. Im Kreidetagebau Wittenfelde, am Südrand der Kernzone, war auch eine Mulde angeschnitten, deren steil aufgerichtete Schenkel die Kreide-Pleistozänfolge unter dem diskordanten M3Geschiebemergel im normalen Verband zeigten. Außerdem weisen in diesem Tagebau Verbiegungen der Schuppenenden, auch bis zum Abriß und Verschiebung nach Nordwesten, auf Versätze an Querstörungen hin (GROTH 1961).

\subsection{Zum inneren Bau der Stauchmoräne Jasmund}

Auch der geringere Aufschlussgrad lässt für die Stauchmoräne Jasmund schon eine wesentlich kompliziertere Architektur im Vergleich zur Stauchmoräne Peski erkennen.

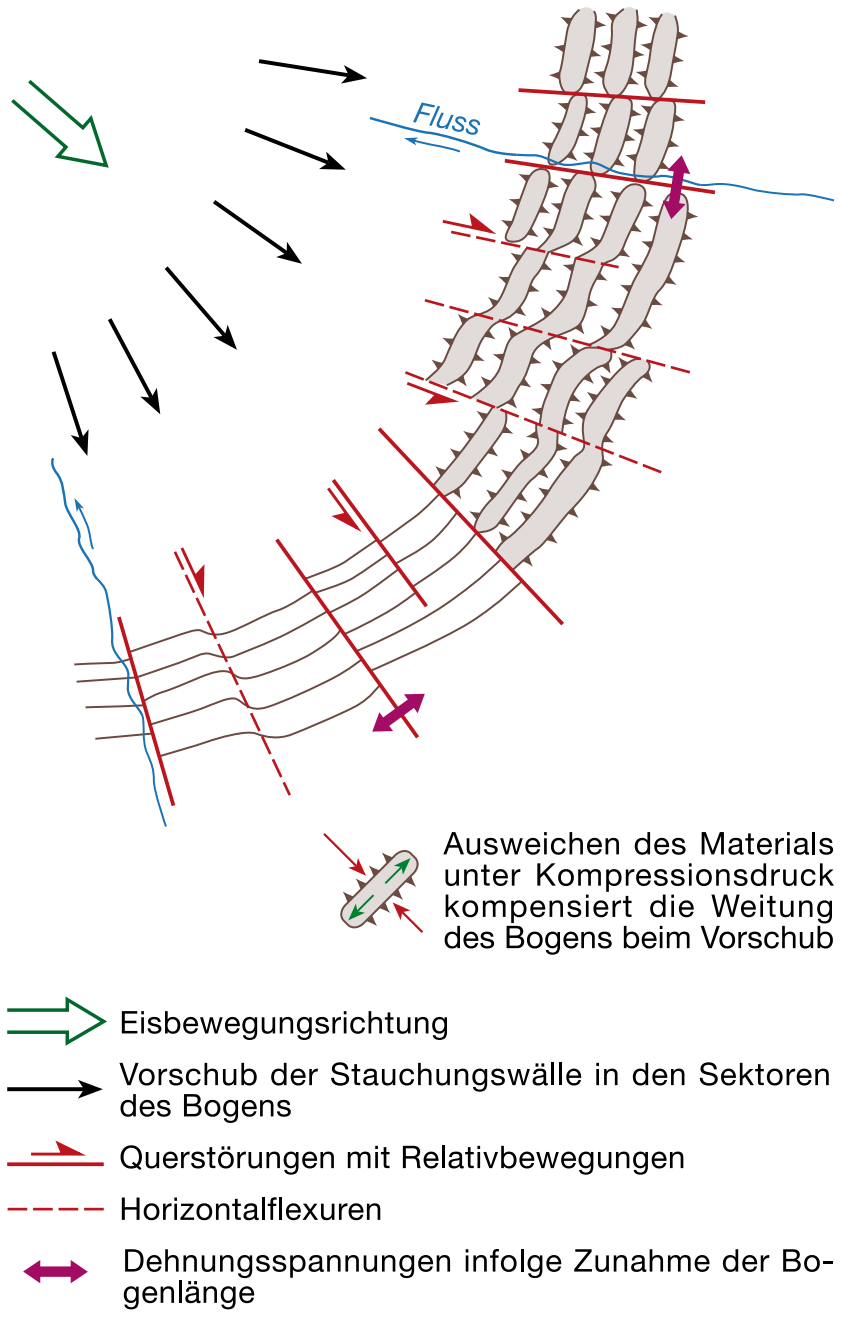

Abb. 9: Architekturmuster (schematisch) des Stauchmoränenbogens (Weitungsbogen) bei Peski.

Fig. 9: Architecture (schematic) of the arcuate push moraine near Peski.

Das schematische Profil durch den Südteil von Jasmund zeigt die vorherrschenden Strukturelemente, die denen der Stauchmoräne Peski gleichen: stehende Isoklinal-, Überschiebungs-, Schlepp- und Pilzfalten (Abb. 10 u. 11) mit Übergängen zu dachziegelartig gelagerten Schuppen.

Eine Besonderheit stellt die leicht nach NE, gegen die Hauptbewegungsrichtung des Eises geneigte Falte des Pleistozänstreifens 4 am Kliff nördlich von Sassnitz dar (Abb. 10, rechte Seite). Durch eine Einbiegung zur Mündung des Lenzer Baches ist sie nahezu rechtwinklig angeschnitten. Diese Strukturform wiederholt sich im Kliff nach $\mathrm{N}$ mehrfach. Der spitzwinklige Anschnitt verzerrt dort die Muldenform stark und täuscht fast horizontale Lagerung der Schichten vor (Ludwig 1954/55: Abb. 9) (Abb. 12 u. 13). Daneben treten am Kliff kompliziertere Deformationsbilder auf. Wiederholt sind in den Kreidewänden des Kliffs Übergänge von rupturellen zu plastisch-fließenden Versätzen kleinerer Dimensionen vom Verlauf der Flintlagen abzulesen.

Für die Interpretation der Architektur der Stauchmoräne ist es wichtig, dass am Ostkliff das Streichen der Strukturen aus südnördlicher Richtung dem Kliffverlauf folgend nach $\mathrm{N}$ in nordwestliche Richtung abbiegt, unter Fallen nach SW, und dass nordwestlich vom Königsstuhl 
A B

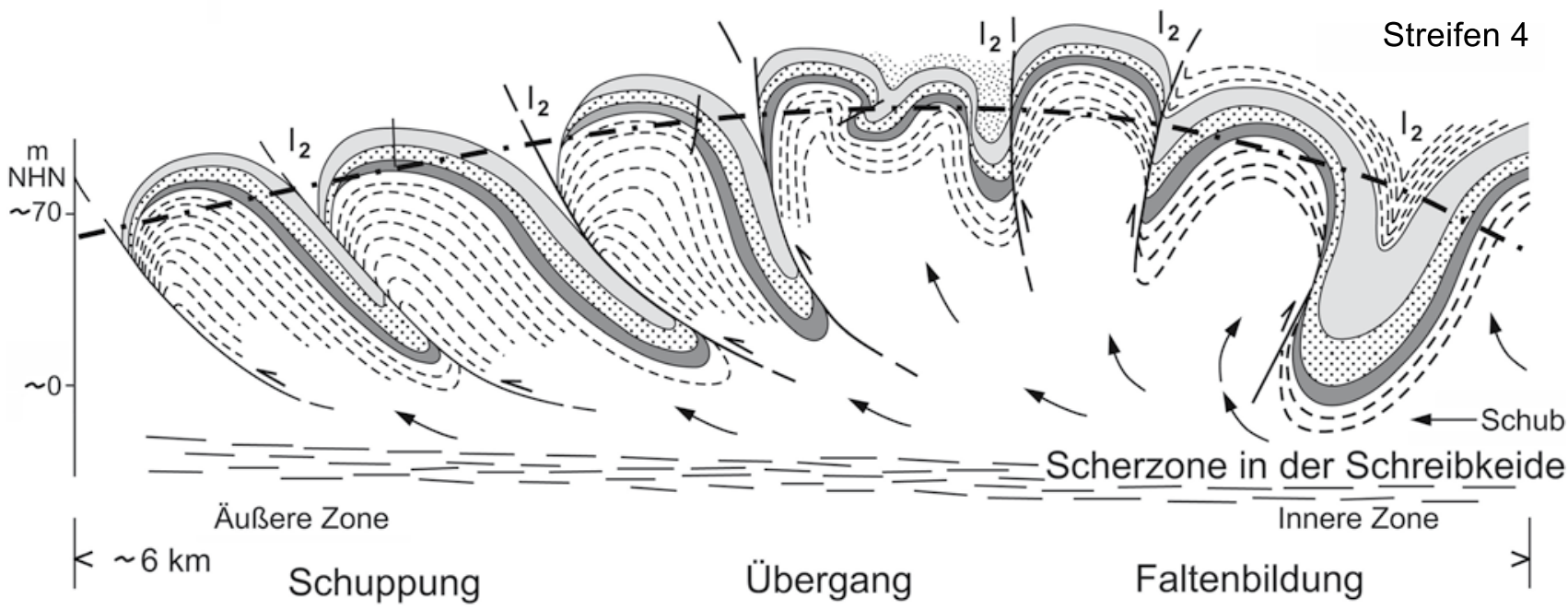

A. O. LUDWIG

济 Schreibkreide (Maastricht)

. $\mathrm{I}_{1}$-Sand und Silt mit Mooslagen

\section{$\mathrm{M}_{1}$-Geschiebemergel}

此 I $I_{2}$-glazifluvialer Kies, Sand und Silt, lokal Bänderton

\section{- - Basis des diskordanten $\mathrm{M}_{3}$-Geschiebemergels}

Abb. 10: Schematisches Profil durch den Südteil der Stauchmoräne fasmund: Mönkendorf bis Streifen 4 am Kliff nördlich von Sassnitz (ohne diskordanten M3-Geschiebemergel, stark überhöht). Die Schleppfalte des Streifens 4 bildet eines der Hauptstrukturelemente der Stauchmoräne (Lage siehe Abb. 14).

Fig. 10: Schematic profile across the southern part of the Jasmund push moraine: Mönkendorf up to stripe 4 at the cliff coast north of Sassnitz (without the discordant layered M3 till unit, strongly exaggerated). The drag fold at Pleistocene stripe 4 shows one of the main structural elements of the push moraine fasmund (Location see fig. 14).

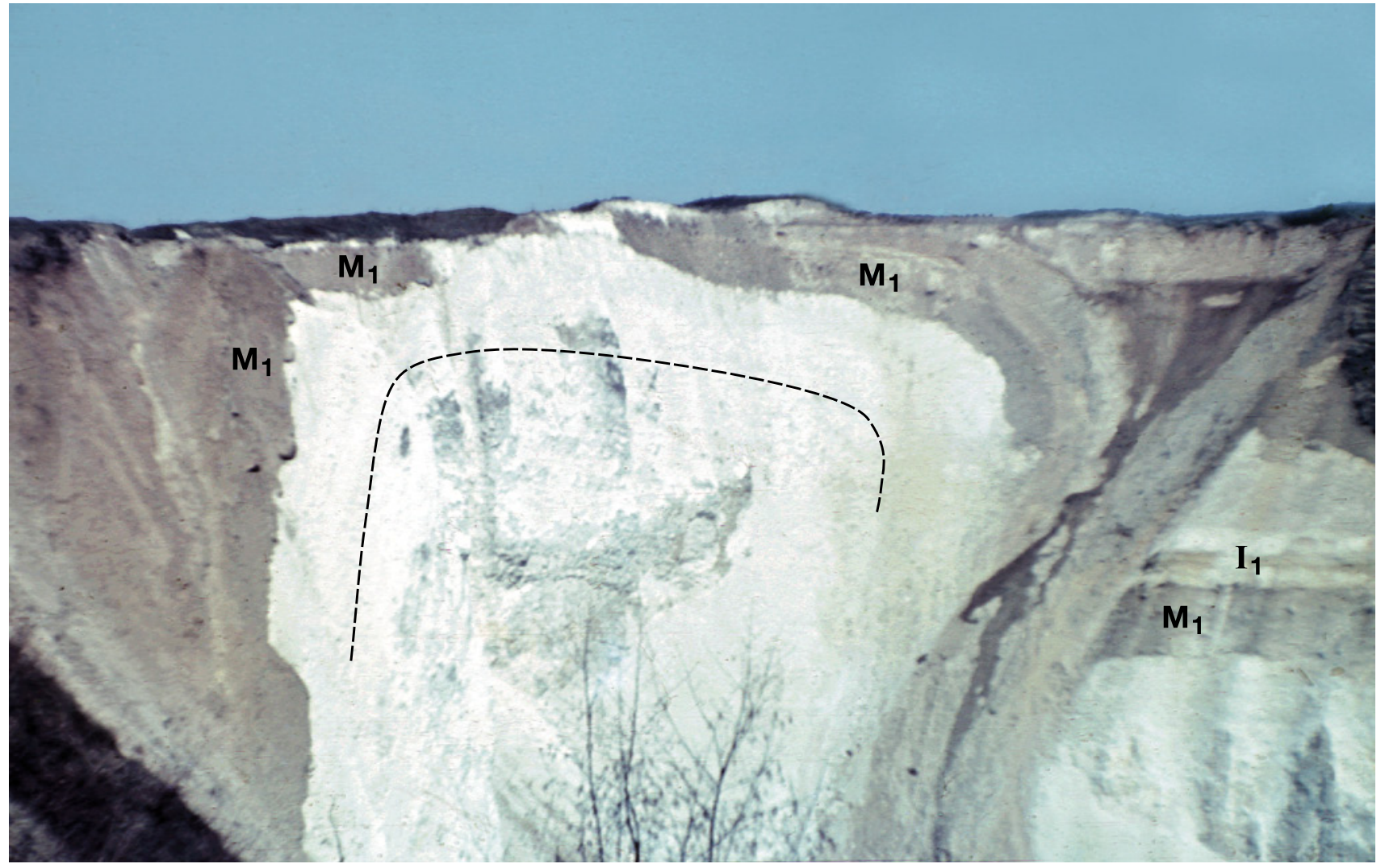

Abb. 11: Pilzfalte (Kreide - M1 - I 1 - Schichten) im auflässigen Kreidebruch Lenz-Berg bei Sassnitz (Foto: A. O. LUDWIG 1953).

Fig. 11: Mushroom shaped fold (chalk - M1 - I 1 - beds) in the abandoned chalk pit Lenz-Berg near Sassnitz (photo: A. O. LuDWIG 1953). 


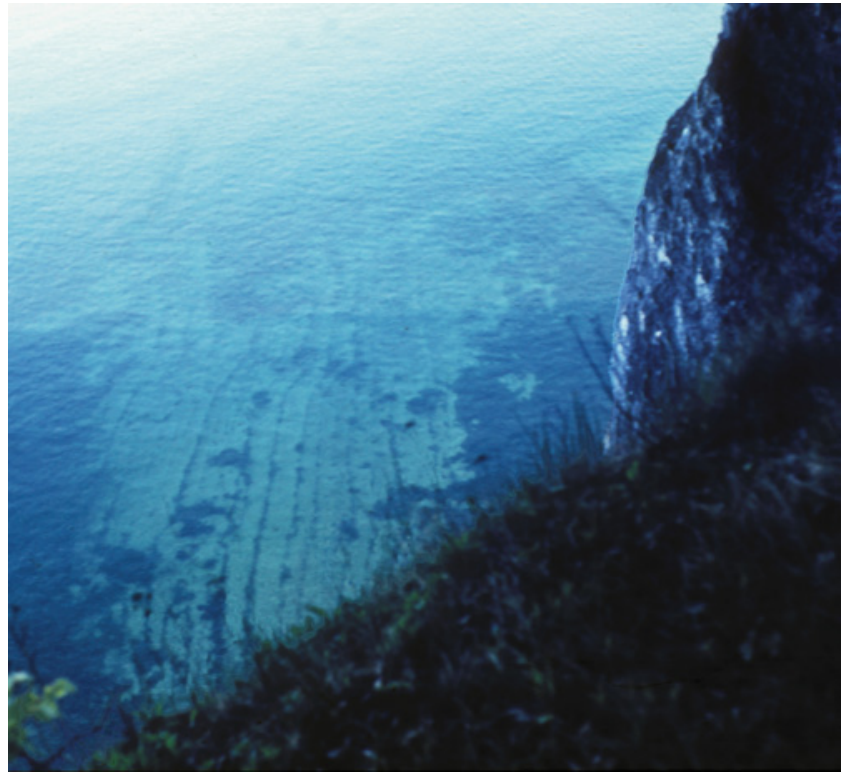

Abb. 12: Streichen der Flintbänder in der Kreide am Ostseeboden unterhalb des Königsstuhls, Stauchmoräne fasmund (Blick vom Hochufer, Foto: A. O. LUDWIG 1960).

Fig. 12: Strike of the flint layers within the chalk at the Baltic Sea floor below the Königsstuhl cliff, push moraine fasmund (seen from up the cliff, photo: A. O. LUDWIG 1960). das Fallen in nordöstliche Richtung umschlägt (Abb. 14) Das nordwestliche Streichen der Schichten in den dort SW-vergenten Falten und Schuppen mit nordöstlichem Fallen setzt sich im Nordteil der Stauchmoräne nach W gegen Glowe hin fort. Es wird von zunehmender Auflösung der Strukturen und Verschleppung von losgelösten Kreideschollen begleitet. Größere Kreideschollen haben noch ihnen aufgelagerte ältere Glieder der Pleistozänfolge im Huckepack mitgeschleppt (Ludwig 2005). Außer den Aufschlüssen am Nordkliff haben das die Bohrungen und Aushubarbeiten für den im vergangenen Jahrhundert geplanten Kanaldurchstich von der Tromper Wiek zum GroBen Jasmunder Bodden gezeigt.

\subsection{Architektur und Genese der Stauchmoräne Jasmund}

Mangels hinreichender Aufschlüsse ist immer wieder, besonders seit GRIPP (1947), die Morphologie der Halbinsel Jasmund zur Erklärung der Bildung der Stauchmoräne Jasmund herangezogen worden. Vorausgesetzt wird dabei, dass die aus der topographischen Karte herausgelesenen Höhenrücken den inneren Bau der Stauchmoräne abbilden, und dass sie aufragende Kreiderücken markieren. Das trifft für die verschiedenen Teile der Stauchmoräne in unterschiedli-

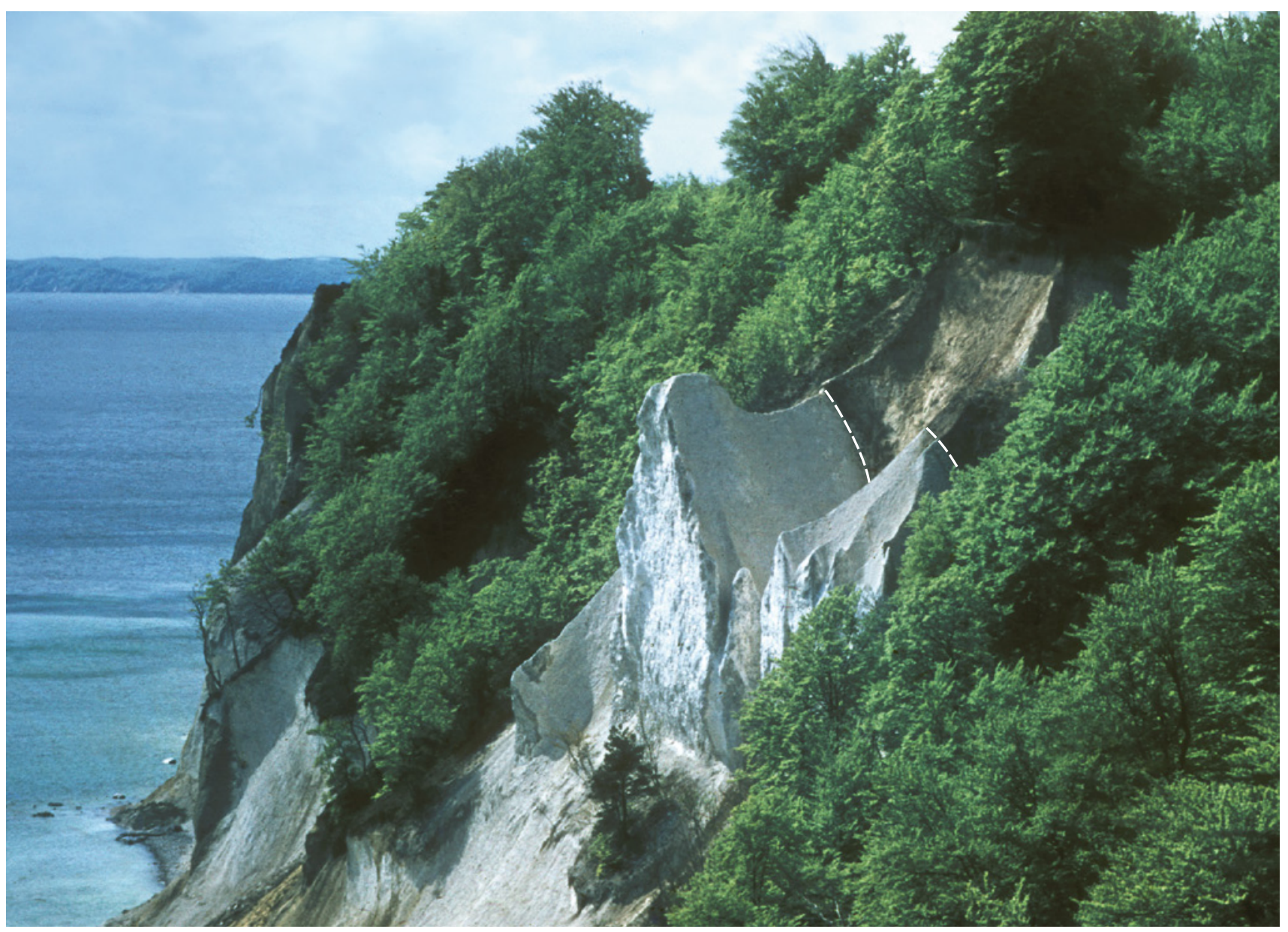

Abb. 13: Kreideklippe "Große Wissower Klinte" nördlich Sassnitz, am 24.02.2005 abgebrochen, rechts davon Pleistozän, Streichen spitzwinklig zum Kliff (Foto: A. O. LuDWIG 1956).

Fig. 13: Chalk cliff "Große Wissower Klinte" north of Sassnitz, fallen down on the 24th of February 2005, Pleistocene beds right side the chalk, strike acuteangled to the cliff contour (photo: A. O. LUDWIG 1956). 


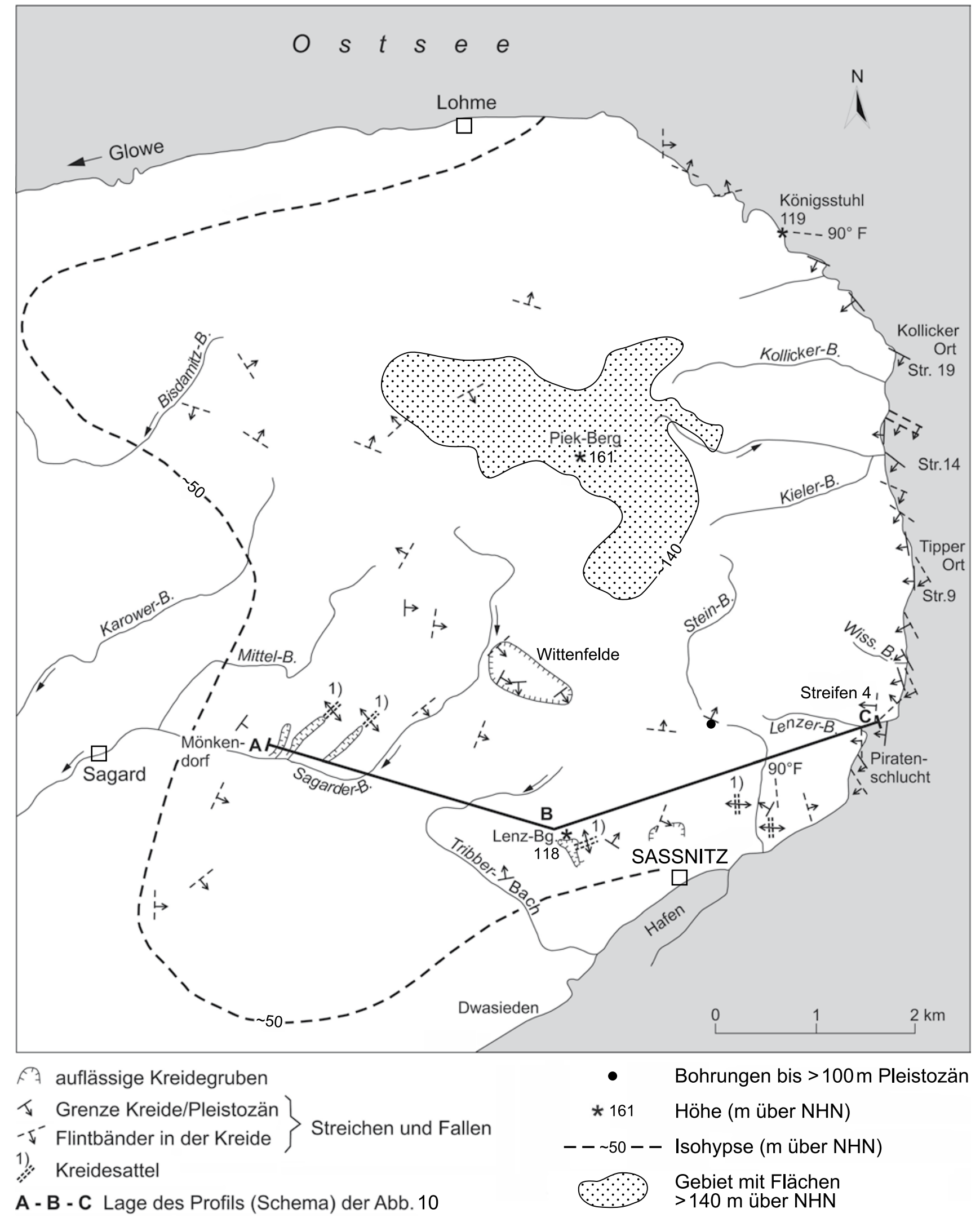

Abb. 14: Streichen und Fallen der Grenzfläche Kreide / Pleistozän (M1-Geschiebemergel) und der Flintbänder in den Kreideschichten der Stauchmoräne fasmund (nach A. O. LUDWIG 1954/55).

Fig. 14: Strike and dip of the boundary chalk / Pleistocene beds (M1 till unit) and of the flint layers within the chalk in the push moraine fasmund (after A. O. LUDWIG 1954/55). 


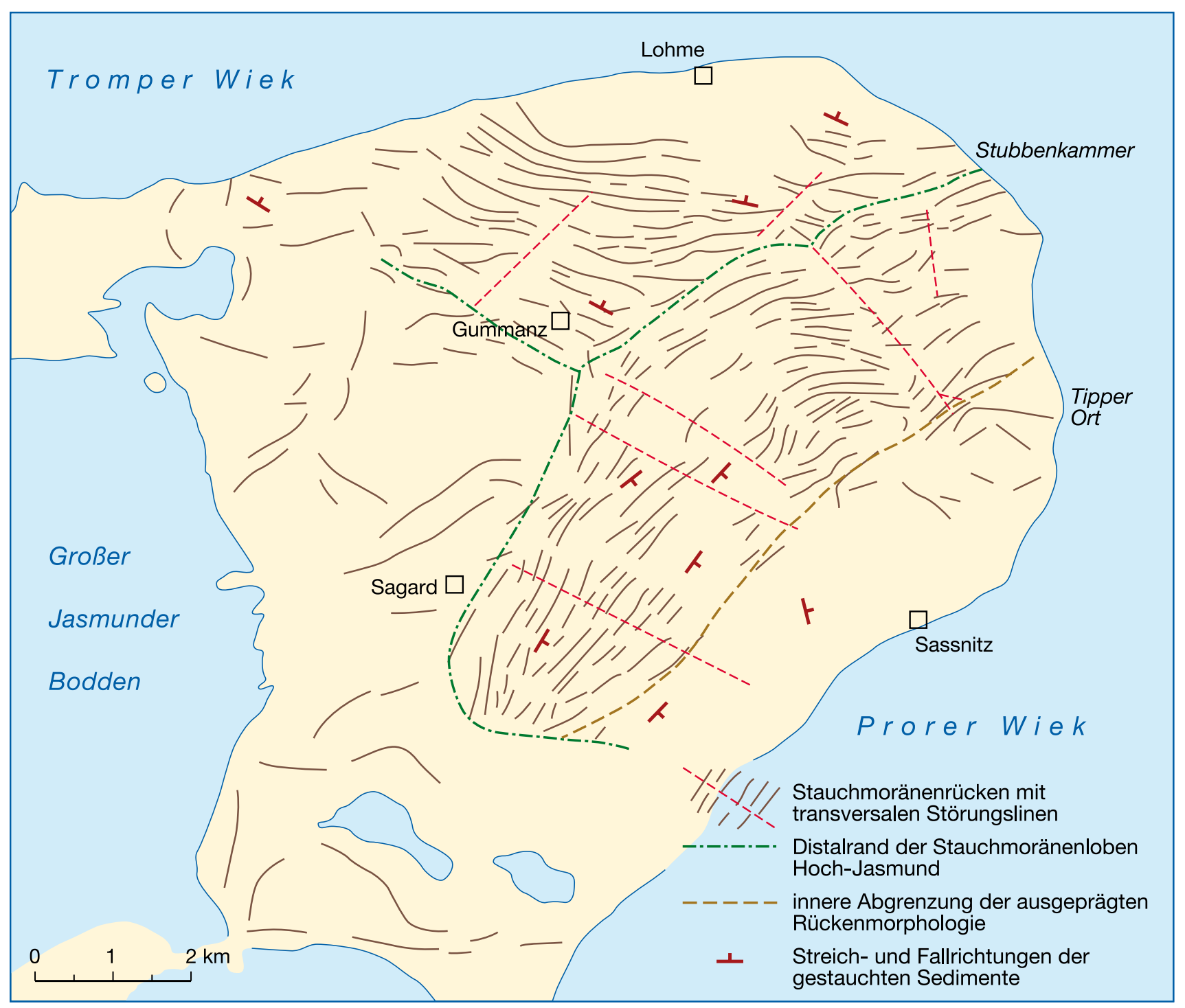

Abb. 15: Stauchrücken-Muster von Hochjasmund (vor allem nach STEINICH 1972 und GROTH 2003).

Fig. 15: Pattern of the push moraine ridges of Hochjasmund (mainly after STEINICH 1972 and GROTH 2003).

chen Graden zu - abgesehen von den subjektiven Einflüssen auf die Verbindung der Höhen zu Höhenrücken. Manchmal weicht ihr Verlauf vom Streichen der Kreidestrukturen ab (s. auch Steinich 1972). Schließlich haben folgende Prozesse das Relief noch verändert: der Eisübergang, teils glättend, teils ausräumend, die vom übergehenden Eis aufgesetzten Ablagerungen sowie Rutschungen und Bodenfließen bis zur Festlegung der Lockergesteine durch die holozäne Vegetationsdecke, um nur die wichtigsten Einflüsse zu nennen.

Unter diesen Bedingungen gibt auch die kartierte Kreideverbreitung (bis $2 \mathrm{~m}$ tief) keinen näheren Aufschluss über den inneren Bau der Stauchmoräne. Am stärksten ist die Kreide im Osten, auf der steilen Luvseite der Stauchmoräne freigelegt, nach Westen ausgewalzt und verschleppt worden (auch die ursprüngliche, inzwischen von der See zurück geschnittene Luvseite muss steil gewesen sein).

Dennoch sind die Beziehungen zwischen den Stauchungsstrukturen und der Morphologie nicht gänzlich verwischt worden. Besonders im Nordteil der Stauchmoräne mit den NE-fallenden Schuppen verlaufen die Hügelzüge noch ziemlich strukturkonform. Südlich der Kernzone, vor allem im SW ist bei flacherem Relief diese Beziehung weniger aus- geprägt. Weitgehend ausgelöscht ist sie im Bereich der Ostküste. Dort prägen E-W-gerichtete Taleinschnitte, die zu den Strukturen quer verlaufen, das Relief. Dieses spiegelt die Strukturen im Kliff nicht wieder. Die Geländerücken müssten dort sonst nordsüdliche Richtungen einnehmen.

Unter Vernachlässigung dieser Befunde vom Ostkliff werden morphologisch eine nördliche und eine südliche Gruppe von E-W verlaufenden Höhenrücken unterschieden, die im W nach NW und nach SW bogenförmig abschwenken (Abb. 15). Sie werden als spitzwinklige Kerbstauchung zwischen einem nördlichen und einem südlichen Teileisstrom interpretiert. Die WSW ausgerichtete Kerbe wird durch das Umschlagen der Fallrichtung am Kliff nordwestlich vom Königsstuhl markiert.

Dass die Stauchmoräne Jasmund letztlich zwei Eisströmen, die, vor allem ihre Flanken, mehr oder weniger gegeneinander gewirkt haben, ihre Entstehung verdankt, ist nicht zu bestreiten. Jedoch hat Ludwig (1954/55) bereits auf die Diskrepanz zwischen glazigener Struktur und Morphologie im Bereich des Ostkliffs hingewiesen. Diese passt nicht zum Modell einer spitzwinkligen Kerbarchitektur. Ebenso wenig passen die dort nach E bis NE gerichteten Vergenzen dazu, 

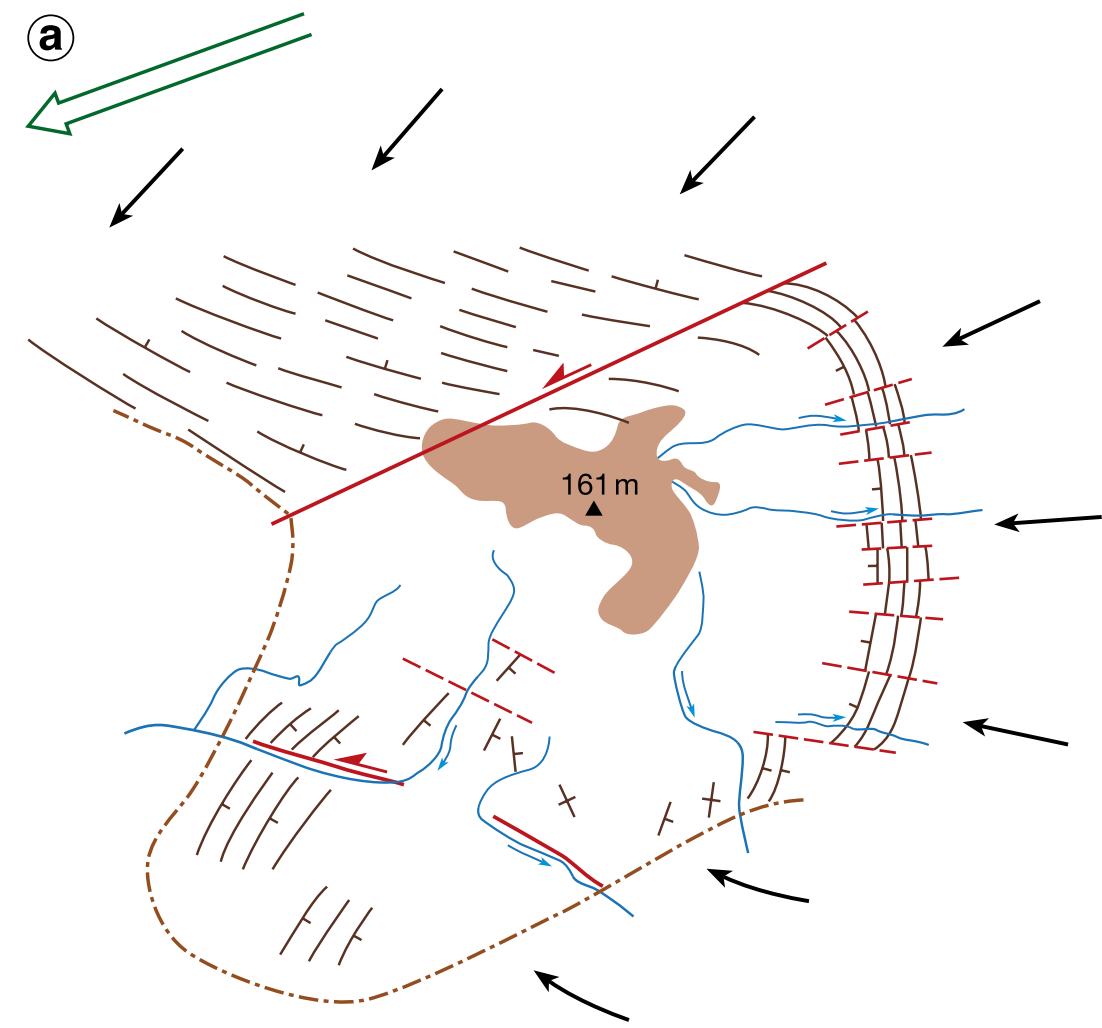

A. O. LUDWIG

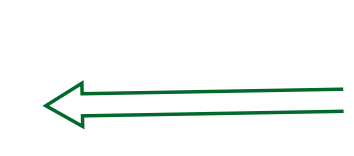

0 $3 \mathrm{~km}$ $3 \mathrm{~km}$
Streichen und Fallen der Falten- und Schuppenstrukturen (Kammlinie)

$\longleftarrow$ Zone stärkerer Querverschiebungen

- - - rupturelle und bruchlose Querversätze

\ höchster Punkt

Gebiet mit Flächen >140 m über NHN

$\longleftarrow$ Bach

Haupteisströme

Schubrichtung des

stauchenden Eises

Abgrenzung der

Flanken der Stauchmoräne

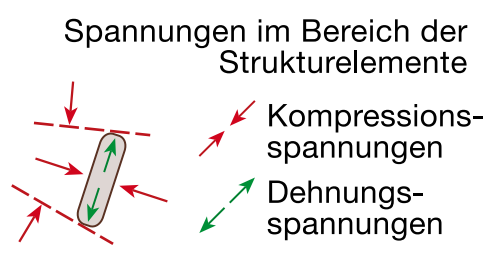

(b)
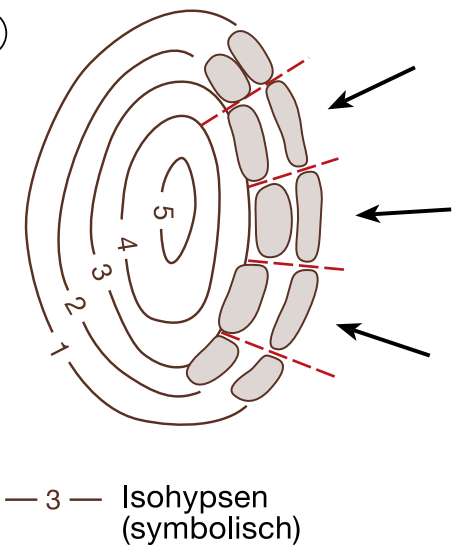

$\bigcirc \bigcirc$ Strukturelemente

---- seitliche Versatzzonen

$\longleftarrow$ Eisschubrichtung

(C)
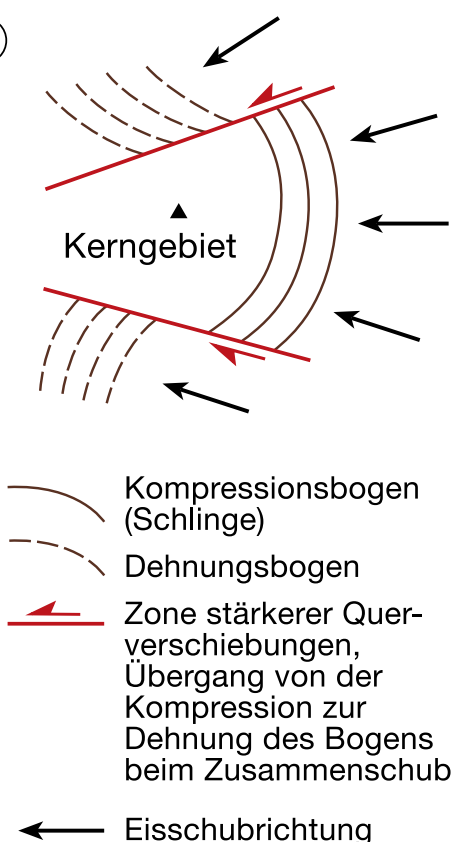

Abb. 16: a - Architekturmuster (schematisch) der Stauchmoräne fasmund; Kompressionsbogen im Kern mit Übergängen zu Weitungsbögen an den Flanken; $b$ - frische schlingenförmige Stauchungswälle um eine Geländeerhebung im Raum von fasmund bis östlich davon (später überprägte Anlage); $c$ - stark vereinfachtes Schema.

Fig. 16: a - Pattern of the architecture (schematic) of the push moraine fasmund; $b$ - early loop-shaped push moraine ridges around an elevated area in the fasmund region (later on reshaped structures); c - strongly simplified scheme.

also dem von dort andrängenden Eis entgegen gerichtet. Die Vertreter der Kerbstauchung erklären das mit einem leichten Schwenk der östlichen Partien des vom südlichen Strom andrängenden Eises nach NE (z.B. BRINKMANN 1953).

Ähnlich wird die Bildung der etwas kleineren Stauchmoräne mit Schreibkreideanteilen Møns Klint zwei Eisströmen aus verschiedenen Richtungen zugeschrieben, die nacheinander und rechtwinklig zueinander stauchend gewirkt haben (PEDERSEn 2000). Die Strukturelemente sind denen in der Stauchmoräne Jasmund im Prinzip ähnlich (Faltenüberschiebungen, Schuppen), infolge der stärkeren glazigenen Durcharbeitung im Detail jedoch komplizierter ausgebildet.

\subsection{Zur Diskussion gestelltes geändertes Genesemodell}

Um die aufgezeigte, wenig beachtete Diskrepanz zwischen glazigener Struktur und Morphologie am Ostkliff besser zu verstehen, wird folgendes modifizierte Modell zur Diskussion gestellt (Abb. 16 a-c):

Dieses Modell sieht eine mehr oder weniger schlingenförmige Anlage erster Stauchwälle vom M3-Eis (s. Abb. 3) um eine topographische Hochlage vor und damit einen nach E konvexen Kompressionsbogen. Ob eine kuppelförmige oder eine in Längsrichtung, etwa NNW-SSE, betonte Erhebung vorlag, bleibt offen. Das primäre topographische Hindernis ist durch die frühen Stauchungen verstärkt und 
zunächst vom Eis im $\mathrm{N}$ und S umflossen (temporärer Nunatak) und nach weiterem Eisanstau überflossen worden. Im Unterschied zum Dehnungsbogen der Stauchmoräne Peski ging die Entwicklung auf Jasmund von einem Kompressionsbogen zwischen zwei Teileisströmen aus. In diesem hat die Verkürzung der Bogenlänge beim Vorschub der Gesteinspakete die Kompressionsspannungen, die beim Zusammenschub der Strukturelemente entstanden waren, verstärkt und ein Ausweichen des Materials nach den Seiten zugunsten der Ausquetschung nach oben verhindert (Abb. 16 a u. c). Deshalb tritt die Stauchmoräne Jasmund mit Höhen bis $161 \mathrm{~m}$ über ihre Umgebung noch nach dem Eisübergang (ähnlich die Stauchmoräne Møns Klint, ohne Eisübergang) morphologisch stärker in Erscheinung als die Stauchmoräne Peski. Das Ausquetschen des Materials nach oben hatte analog zu den Salzstöcken lokal Dehnungen zur Folge. Darauf wiesen einzelne Risse, offene und auch mit Kreidebruchstücken und „Ton“ verfüllte Spalten in den Kreidegruben hin (Kreidegruben Galitz und Küster'scher Bruch, WAHNSCHAFFE 1882, zitiert in Ludwig 1954/55, STEINICH 1972).

Den Kompressionsbogen des Anlagestadiums haben ähnlich wie im Bogen Peski Querstörungen gegliedert. Diese werden in den Querversätzen der Strukturen „Streifen" am Ostkliff deutlich. Lokal zeichnen sie sich auch im Innern der Stauchmoräne ab (s. u.) (KeILHAck 1914 tektonisch interpetiert; Ludwig 1954/55 und STEINICH 1972 glazitektonisch interpretiert).

Beim weiteren Zusammenschub hat das Eis, das nördlich und südlich der Hochlage stärker und rascher vordrang, die frühen Stauchwälle überformt. Vor allem wurden die schwächer herausgehobenen Flanken der frühen Anlage vom Eis überwältigt, an der Kernzone entlang nach W geschleppt und an Seitenverschiebungen und Flexuren auseinandergezogen. Zugleich entwickelte sich ein Übergang zu unvollständigen Dehnungsbögen an den Flanken der im $\mathrm{N}$ und $\mathrm{S}$ weiter vordringenden Eisströme. Neue Falten- und Schuppenstrukturen wurden mit abnehmender Intensität und Steilstellung außen an die Kernzone angebaut (Abb. 16 a, c). Die Analogien zu endogenen Faltenund Überschiebungsgürteln sind auffallend (ScHARF 1933, LudWig 1954/55, BERTHELSEN 1979).

Dieses Modell stützen folgende Befunde: Im Nordflügel der Stauchmoräne verlaufen die Hügelzüge WNW. Wie Groth (2003) gezeigt hat, zeichnen diese die glazigenen Strukturen und deren Schleppung nach W entlang dem südlich vorgelagerten, entgegen gerichteten Stauchungsbogen (im hier vorgestellten Modell die Kernzone der Stauchmoräne, Verf.) noch relativ gut nach. Hier hat der Eisstrom, der die frühen Stauchwälle umfloss, zwischen seiner Südflanke und der Kernzone einen unvollständigen Dehnungsbogen angefügt. Dessen größte Höhen liegen im E, wo die Stauchung deutlich gegen das südlich gelegene Hindernis Kernzone gerichtet war. Gegen NW wird der Bogen mit wachsendem Abstand von dem Widerlager im $S$ niedriger. Zudem hat das später übergehende Eis dort die Strukturen zunehmend überformt und zerstört.

Ähnliche Beziehungen zwischen den Strukturen und der Form der Geländeoberfläche hat CARLÉ (1938) festgestellt: die größten Stauchfalten liegen im Bereich der höchsten Geländeerhebungen (Mövenbergkliff, Schönhagenkliff). Das ist auch an den Stauchmoränen Ristinge Klint und Stol- tera, beide vom Eis gekappt, jedoch ohne diskordanten Geschiebemergel, zu beobachten (KöSTER 1960, LUDWIG 1964).

Der Südflügel der Stauchmoräne ist an einer breiteren Zone mit rupturellen und nichtrupturellen seitlichen Verschiebungen gegen den Kern abgesetzt. Diese Zone markiert hier den Übergang vom Kompressionsbogen im Kern zum unvollständigen Dehnungsbogen südlich davon, an der Nordflanke des südlichen Teileisstroms. Dessen westvergenter Schuppenbau tritt morphologisch weniger in Erscheinung. Er ist vom übergehenden Eis stärker eingeschliffen worden und wird ebenfalls durch Querstörungen untergliedert.

Den etwas späteren Anbau dieses Flügels macht die Entwicklung seines Rücklandes bis zur Küste deutlich: Dort sind Kreideschollen verbreitet, die zum Teil in I2-Schichten eingepresst worden sind (GROTH 2003). Sie entstammen offenbar glazigenen Strukturen mit Kreideanteilen, die das M3-Eis zuvor weiter ostwärts geschaffen hatte und wieder zerstört hat. Danach sind unter der wachsenden Auflast der I2-Vorschüttsedimente und des andrängenden M3-Eises die westlich dieser Schollenzone folgenden Schuppenstrukturen im Südflügel der Stauchmoräne aufgepresst und zusammengeschoben worden. Das geschah im Fortbau der Stauchmoräne nach außen. Damit sind auch die Strukturen des Südflügels gegenüber der Kernzone zeitlich verzögert an diese angefügt worden. Festzuhalten ist, dass der Stauchungsprozess damals auch in der Kernzone noch nicht abgeschlossen gewesen sein musste, aber auf die Versteilung der Strukturen beschränkt war. Für einen weiteren Fortbau der Kernzone nach außen (Westen) war das Hindernis zu stark geworden. Diese Prozesse haben sich zeitlich mehr oder weniger überlappt.

Die intensive Durcharbeitung der Kreide- und Pleistozänschichten im Rücken der Schuppenzone im Südflügel der Stauchmoräne zeigt das Kliff zwischen Dwasieden und Mukran im Nordwesten der Prorer Wiek. Hier handelt es sich um betont horizontale Verknetungen und Auswalzungen der Schichten mit Kreideanteilen bis zur Schlierenbildung wie sie die Bewegungsdynamik an der Basis des vordringenden Inlandeises entstehen lässt. In der Nähe des Eisrandes wirken Vorschub und Belastung weitgehend gemeinsam. Ähnliche Deformationen sind im Kliff südlich vom Ort Vitt an der Südflanke des Kreidekomplexes am Kap Arkona entwickelt (Ludwig 1954/55, Taf. IV, Abb. 3-6, 1964 und 2006) und an der Südflanke der Stauchmoräne Møns Klint (Houmark-Nielsen 1994).

Die auf Jasmund lokal bis einige $10 \mathrm{~m}$ mächtigen, generell eisrandnahen I2-Sdimente, unter anderem Bänderschluffe, sind in der kurzen Spanne zwischen der Ablagerung des M2-Geschiebemergels und der Stauchung durch das M3-Eis, in einigen Vorkommen noch während der Stauchung, zum größten Teil rasch und in großer Mächtigkeit glazifluvial aufgeschüttet worden. Der Eisrand war in der Nähe verblieben und dort hatte sich das Eis tiefer in den Untergrund, bis in die Kreide, eingeschürft. Das war im Ansatz zum erneuten Vorstoß geschehen, der die Stauchmoräne geschaffen und die diskordante M3-Moräne hinterlassen hat. Der M2-Geschiebemergel enthält noch keine Kreideschollen, nur Schollen pleistozäner Sedimente (Cyprinenton, Limnocythere-Ton u. a.). Die I2-Schichten führen schon wenig über dem M2-Geschiebemergel Kreide- und Flintmaterial erheblich reichlicher als dieser (LuDwig 1964). 
Südlich des Südflügels der Stauchmoräne hat das Eis das in der Prorer Wiek aufgeschürfte Material weiter nach Westen verfrachtet und zu den Höhen im Raum von Bergen aufgehäuft (LuDwig 2004).

GRIPP (1955) hat von morphologischen Untersuchungen in Schleswig-Holstein ausgehend schon Stauchungen an Einbuchtungen des Eisrandes als schlingenförmige Eisrandkerben ausgeschieden. In der Stauchmoräne Jasmund sah er eine „Schlingengabel“, verband aber damit eine spitzwinklige Kerbstauchung im Zwickel zwischen zwei gegeneinander gerichteten Eisloben.

Das Modell der mehrphasigen Stauchung mit schlingenförmiger Anlage im Kern und verzögertem Anbau des Nord- und des Südflügels ermöglicht eine plausiblere Erklärung der E bis NE-Vergenzen der glazigenen Strukturen im Ostkliff. Mit der starken Aufpressung der Schichten im Zentrum des Schlingenbogens staute sich das Eis vor dem wachsenden Hindernis und auch der mitwachsende Druck konnte die Strukturen innerhalb des Kompressionsbogens nur zusammenpressen und steiler aufrichten, vor allem auf der Luvseite. Das Material wich, dem geringsten Widerstand folgend, nach oben aus. Das kann bis zur leichten Neigung der aufquellenden Falten gegen die Eisstirn vor der Kernzone der Stauchmoräne geschehen und dürfte für den Bereich des Ostkliffs einschließlich seines inzwischen an die See verlorenen Teils zutreffen. Unter Bezug auf die Darstellungen von GRIPP (1929, Hamburger Spitzbergen-Expedition) erwähnt CARLÉ (1938) glazigene Stauchfalten, die auf das Eis zu gerichtet waren. Diese Neigung der Strukturen gegen das Eis versteht sich zwanglos, da das Eis seine größte Mobilität und Vorschubkraft in seinen unteren Partien erreicht, dort, wo der Einfluss der Bodenreibung sich verliert. Es entsteht eine Art von Unterschiebungen (Ludwig 1954/55).

Der steile Zusammenschub der Schichten in der Kernzone der Stauchmoräne geht auch aus Brunnenbohrungen im Steinbachtal nördlich von Sassnitz (südlich bis südwestlich vom Schlossberg, auflässige Kiesgrube) hervor (Abb. 14). Die tiefsten dieser Bohrungen reichen bis $102 \mathrm{~m}$ (Hy SAD I/1914, Landesbohrdatenspeicher LUNG MV) und $116 \mathrm{~m}$ unter Terrain, das ist bis $20 \mathrm{~m}$ unter den Ostseespiegel. Diese Bohrungen haben nur Pleistozänsedimente durchsunken.

Der schwache letzte Eisvorstoß im südwestlichen Ostseegebiet hat nur in tieferen Randteilen von Nordügen deutliche Spuren hinterlassen und auf Jasmund nur niedrige Teile der NW-Flanke der Stauchmoräne überfahren. Hochjasmund blieb eisfrei. Wahrscheinlich haben Toteisfelder das Vordringen des M4-Eises im Raum Rügen verhindert (Ludwig 2004). Der nördliche Arm dieses Eisvorstoßes hat die Stauchmoräne Dornbusch (Hiddensee) geschaffen, das nochmalige Anschwellen des südlichen Armes in der Oderbucht die Stauchmoränen der Inseln Usedom und Wolin.

Eine Stauchung unter dem Eis als Hauptakt der glazigenen Strukturbildung ist für die Stauchmoräne Jasmund aus gravitativen, strukturellen und morphologischen Gründen nicht zu vertreten: Da die deformierten Gesteinsmassen höhere Dichte haben als das Eis (auch mit etwas Schutt beladenes) ist eine so stark morphologisch wirksame und steile Aufstauchung wie im Falle der hochaufragenden Stauchmoräne Jasmund (ähnlich Møn) unter einer Inlandeisdecke kaum vorstellbar. Die dafür notwendige Hubleistung müsste allein durch den Abbau von potentieller Energie im Eis er- bracht werden. Dagegen ist das Hervorpressen von Gestein am Eisrand unter der zunehmenden Last durch das anwachsende vordringende Eis physikalisch plausibel und von rezenten Gletschern bekannt. Dort wirken Belastung und Vorschub zusammen. Auf die Beteiligung von Grundbrüchen deuten oft eisauswärts ansteigende Strukturen in den deformierten Schichten hin, die quasi die im Eis zu dessen Rand hin ansteigenden Scherflächen fortsetzen (KUPETZ 1997).

Strukturell spricht gegen eine Bildung der Stauchmoräne Jasmund unter dem Eis, dass die Schmelzwassersande und -kiese der I2-Schichten zusammen mit den älteren pleistozänen Schichten und der Schreibkreide in die Stauchung einbezogen sind (Abb. 3). In der (auflässigen) Kiesgrube am Schlossberg nördlich von Sassnitz reichen sie bis in $118 \mathrm{~m}$ NHN. Ihr Reichtum an Flintgeröll und Kreidebröckchen - im Unterschied zum liegenden M2-Geschiebemergel zeigt, dass die Kreide kurz vorher schon am Eisrand aufgeschürft worden und der Zerstörung durch Schmelzwässer ausgesetzt war (LuDwig 1954/55).

Eindeutig unter übergehendem Eis entstandene glazigene Strukturen zeigen im wesentlichen horizontale, in Richtung der Eisbewegung gestreckte Durchbewegungsbilder mit Sedimentverknetungen, liegenden Falten, Auswalzungen bis zur Bildung von Schlieren und Boudinagen (BERTHELSEN 1979) sowie Lösung und Verdriftung von Schwärmen von Sedimentschollen. Derartige Strukturen finden sich oft auch in vom Eis überwältigten Flankenregionen von Stauchmoränen. Beispiele liefern die Kliffstrecken zwischen Sassnitz und Mukran/Jasmund (Ludwig 1954/55, 1964, Abb. 31), bei Klintholm/Insel Møn (Houmark-Nielsen 1994), der Insel Poel/Westmecklenburg (LuDWIG 1964, RüHBERG 1969), der Insel Greifswalder Oie (KNAUst 1995). Oft belegt eine diskordante Geschiebemergeldecke den Eisübergang.

Eine deutlich von Geländeunebenheiten vorgezeichnete Lobierung zeigt auch die Rehburger Eisrandlage (Norwestdeutschland). Sie bildet eine Kette von sieben W-E verlaufenden Stauchmoränenbögen mit ausgeprägten Stauchungen in einigen ihrer Zwickel. Dort hat der spätere Eisübergang die morphologischen Effekte weitgehend ausgelöscht. In den einzelnen Stauchungsbögen nimmt die Intensität der Deformation ebenfalls von innen nach außen ab (Schuppung bis flachwellige Faltung) (RICHTER et al.1951).

\subsection{Bemerkungen zur Morphologie}

Auch die Morphologie im Bereich der Ostküste (Luvseite) fügt sich dem vorgestellten Modell zwanglos ein. Dabei ist davon auszugehen, dass das anwachsende Eis auf die Stauchungswälle der Kernzone nicht in geschlossener Front übergegriffen hat, sondern dass es auf der steilen Luvseite zunächst schmale Eiszungen auf das frisch geschaffene Hindernis, den temporären Nunatak, hinaufgeschoben hat. Diese folgten bevorzugt den ausgeprägteren Querstörungszonen, an denen die glazigenen Strukturen seitlich versetzt und die Gesteinsgefüge gelockert worden waren. Entlang dieser Querzonen haben die aufsteigenden Eiszungen kurze U-Täler ausgeschürft. Unter den späteren periglazialen Bedingungen waren diese Täler teilweise aufgefüllt worden, bis die Vegetationsdecke das Material festgelegt hatte. Im humiden Klima des Holozäns haben die Bäche in die flachen Talböden Vförmige Talübertiefungen eingeschnitten (LuDwig 1954/55). 
Die Rücken zwischen den ungefähr E-W verlaufenden Bachtälern queren die glazigenen Strukturen im Kliffbereich. Dort, auf der Luvseite der Stauchmoräne, ist die EW-Morphologie stärker vom übergehenden Eis geprägt worden als von den Strukturen. Diese haben die Geländeformen in den an die Kernzone angefügten Flankenbereichen der Stauchmoräne deutlicher mitbestimmt.

Gemäß der steilen Form der Luvseite der Stauchmoräne, die der Küstenrückgang nur im unteren Teil des Kliffs verstärkt hat, liegen ihre höchsten Flächen, über 140 m NHN, und die Wasserscheide näher an der Luvseite. Nach E entwässern nur kurze Bäche, nach W (und S) erheblich längere (Abb. 14 u. 16a). Das Areal mit den höchsten Flächen biegt im $\mathrm{E}$ nach $\mathrm{S}$ ab und begleitet in einigem Abstand bogenförmig die Kontur des Ostkliffs. Offenbar spiegelt sich darin bis zu einem gewissen Grade der Kompressionsbogen der Anlage mit seinen besonders hoch herausgepressten Gesteinspaketen wider. Die scharfen Richtungsänderungen des Sagarder-, Tribber- und Steinbaches aus nordsüdlichen in ostwestliche beziehungsweise westöstliche Laufabschnitte (Abb. 14) dürften an Querstörungszonen gebunden sein. Zwischen beiden Seiten des E-W-Abschnittes des Sagarder Baches haben die Erkundungsarbeiten horizontale Versätze der nördlichen Schuppenstrukturen nach W ergeben (GROTH 2003).

Die hohe Aufragung der Kernzone der Stauchmoräne Jasmund über ihre Umgebung im Vergleich zur Stauchmoräne Peski geht auf die doppelte Einengungswirkung bei der Stauchung im Kompressionsbogen zurück: einmal beim Zusammenschub der Schichten zu den Falten- und Schuppenstrukturen und zum anderen Mal beim Vorschub vor allem der Flanken des vom Untergrund abgescherten Gesamtkomplexes gegen zentralere Teile des Kompressionsbogens der Anlagephase. Die betroffenen Schichten wurden dabei zwangsläufig höher nach oben ausgepresst als im Dehnungsbogen bei Peski.

Das Gebiet mit den höchsten Aufragungen, über 140 m NHN, folgt nicht genau der Naht zwischen dem Kern- und dem nördlichen Flankenteil der Stauchmoräne. Das lässt darauf schließen, dass die stauchenden Kräfte des nördlichen Eisstromes das Material nicht so stark herausgepresst haben wie das zuvor im Ostbogen der Schlinge geschehen war.

In der Südflanke werden diese Höhen nicht erreicht. Dort ist die Grenze zum Kern der Stauchmoräne als breitere Zone mit seitlichen Versätzen ausgebildet (s. Groth 2003). Außerdem war der Zusammenschub dort stärker nach W als gegen den Kern der Stauchmoräne gerichtet.

\section{Beziehungen der Stauchmoränen Peski und Jasmund zur Struktur und zur neotektonischen Mobilität ihres Untergrunds}

\subsection{Stauchmoräne Peski}

Die Landschaftsformen in Belorussland werden im wesentlichen von den glazialen Formen bestimmt. Diese sind weitspannigen tektonischen Strukturen aufgesetzt, deren Entwicklung bis ins Quartär reicht. Infolge langzeitiger tektonischer Aufwölbung Westbelorusslands liegt im Raum Peski der kristalline Untergrund nur 200-300 m, lokal nur 100 m unter Terrain (Levkov 1980). Das Kristallin wird von Oberkreide transgressiv überlagert. Lokal liegt Paläo- gen unmittelbar auf dem Kristallin. Dessen Oberfläche und die Schichtgrenzen der Decksedimente einschließlich der Pleistozänbasis steigen nach S bis SE zum Ukrainischen Plateau hin leicht an. Die Mächtigkeit der Kreide wächst nach W bis zur Grenze nach Polen von 80 auf $150 \mathrm{~m}$ an.

Das Gebiet um Peski zeichnet sich durch langfristige, bis zur Gegenwart andauernde tektonische Hebungstendenzen aus. Die Hebungen werden nach der großen Lücke zwischen dem Kristallin und der auflagernden Oberkreide an der lückenhaften Oberkreide-Tertiärfolge deutlich (unvollständiges Campan, lokal wenig Maastricht, Tertiär erst ab Obereozän vorhanden und Neogen wahrscheinlich ebenfalls lückenhaft).

Auf die Beteiligung ruptureller Vertikalbewegungen während der Oberkreide weist ein Konglomeratgeschiebe mit Granatgneisgeröllen hin (Fundpunkt s. Abb. 17). Dieses Geschiebe ist lithologisch den Konglomeraten in der Oberkreide von Schonen/Südschweden sehr ähnlich. Die Foraminiferenfauna in der Kreidematrix des Geschiebes wies Santon-Alter für das Konglomerat aus (Prof. HeRRIG, Greifswald, in Ludwig \& LEVKov 1989). Das bedeutet, dass damals Kristallin in der Region zumindest lokal freigelegt worden war, und dass zur Zeit der mehraktigen bruchtektonischen Bewegungen während der Oberkreide in der Westeuropäischen Tafel sowie am Südwestrand der Osteuropäischen Tafel und auch östlich davon innerhalb der Tafel Rupturen reaktiviert worden waren. Der Fundpunkt des Geschiebes liegt - wohl kaum zufällig - in der Nähe einer nach LEvkov \& KARABANOv (1996) auch neotektonisch aktiven, SW-NE gerichteten Hauptbruchzone (Brest-Minsk-Witebsk) (Abb. 17).

In der folgenden Entwicklung sind die Tertiärsedimente bis auf kleine Restflächen erosiv und exarativ abgetragen worden. Das ist ebenfalls ein Hinweis auf eine relative Hochlage dieser Region Westbelorusslands zu diesen Zeiten. In Übereinstimmung damit weisen die Isobasen der neotektonischen Hebung (in Belorussland seit dem Ende des Oligozän gerechnet) im Bereich der SW-NE Hauptbruchzone einen erhöhten Gradienten aus. Die Lage der Stauchmoräne Peski im Bereich dieser Zone ist auffällig, und auch das Flussnetz lehnt sich an das Bruchnetz im Untergrund an. Vor allem deuten unvermittelte Änderungen der Laufrichtung, zum Beispiel des Neman, auf differenzierte junge Vertikalbewegungen von Krustenblöcken in diesem Raum hin. Die Wasserscheide zwischen Ostsee und Schwarzem Meer verläuft einige $10 \mathrm{~km}$ südlich bis südöstlich von Peski (Abb. 17). Diese Lagebeziehungen können nicht als rein zufällig gewertet werden. LEVKOV \& KARABANOv (1996) nehmen für das Mittelpleistozän eine tektonische Reaktivierung von Brüchen an, die von glaziisostatischen Vertikalbewegungen überlagert worden sind. Die glaziisolatischen Anteile am Gesamteffekt lassen sich bisher nicht näher bestimmen.

\subsection{Stauchmoräne Jasmund}

\subsubsection{Zur Frage einer tektonischen Hochlage Jasmunds vor der Stauchung}

Als Ursache für die Bildung der Stauchmoräne Jasmund ist wiederholt eine tektonische Hebung angenommen worden, die das Relief verstärkt und Angriffsflächen für das vordringende Eis geschaffen hatte. Da das Eis mehr- 
mals über die Region Jasmund hinweggeglitten war, ohne auf den Kreideuntergrund nennenswert einzuwirken (M1- und M2-Eis und frühere Eisdecken) wurde das tektonische Ereignis in der kurzen Zeitspanne zwischen der Ablagerung des M2-Geschiebemergels und dem Andringen des M3-Eises angesetzt. Dieses tektonische Konzept ist mit dem Argument abgelehnt worden, dass in den Bohrungen in Ostrügen an der Oberkreidebasis keine vertikalen Sprünge festzustellen sind, nur ein leichter stufenloser Anstieg gegen SW. Dieses ist nicht schlüssig. Da die gestauchten Schichten etwa auf die Hälfte zusammengeschoben und wahrscheinlich auch insgesamt noch ein Stück von ihren Wurzeln weggeschoben worden sind, müssen die vermissten tektonischen Versätze im Seegebiet östlich um Jasmund gesucht werden. Dort steht nur eine Bohrung, und das reicht nicht aus, um eine tektonische Anhebung während des Pleistozän auszuschließen. Auch der zeitliche Ansatz im mehr oder weniger eisfreien Intervall vor der Stauchung ist nicht zwingend. Schließlich muss eine Hochlage zur Einbuchtung und Teilung des Ostseegletschers in die beiden stauchenden Eisströme geführt haben. Die hoch herausragende Insel Bornholm, in $>80$ km Distanz von Jasmund, dürfte zu weit entfernt gelegen sein, um als Strompfeiler allein noch als Ursache für diese Teilung gewirkt zu haben. Für die schlingenförmige Anlage der Stauchmoräne Jasmund kommt eher eine näher gelegene oder näher heranreichende Geländeerhebung in Frage.

Eine relative Hochlage des Gebiets von und um Jasmund im Pleistozän zeichnet sich wie folgt ab: Während das Cyprinentonmeer der Weichselkaltzeit nördliche Teile Rügens überflutet hat, fehlen auf Jasmund in den stratigraphisch äquivalenten I1-Schichten marine Einschaltungen. Nur im Küsterschen Kreidebruch (STRUCKMANN 1879) und bei Kluckow am Nordkliff (STEINICH 1992) sind einzelne umgelagerte marine Mollusken, mit limnischen Faunenresten vermischt, gefunden worden. Das deutet darauf hin, dass dieser Raum während des I1-Intervalls höchstens randlich und kurzzeitig marin beeinflusst war.

Weiter fanden sich eine Scholle Cyprinenton mit mariner Fauna im M2-Geschiebemergel im Pleistozänstreifen 5 am Kliff nördlich von Sassnitz (Ludwig 1964) und drei Schollen mit vergleichbarem Mikrofossilinhalt im Kliff der Insel Greifswalder Oie in der Oderbucht (OBst \& ANsORgE 2010). Zusammen mit dem stratigraphisch wahrscheinlich äquivalenten marinen Ton, der nordnordwestlich von Rügen im Seegebiet von Kriegers Flak um -40 m wenig tiefer als in Nordrügen erbohrt worden ist (ANJAR et al. 2010), ergibt sich, dass das Cyprinentonmeer im N und E um Rügen herum nach $\mathrm{S}$ bis in die Oderbucht gereicht hat. Damit zeichnete es eine damals schon bestehende Depression im Odermündungsgebiet nach. Diese hat während der Weichselvereisung den Vorstoß des Odergletschers weit nach S ermöglicht und die entsprechend weite Ausbuchtung der Pommerschen Eisrandlage nach S.

Zusammen mit Schollen aus anderen I1-Schichten, zum Beispiel des Limnocythere-Tons, zeigen die Schollen im M2-Geschiebemergel von Jasmund und Arkona, dass das M2-Eis schon pleistozäne Schichten aufgeschürft, aber nach dem geringen Gehalt an Kreidematerial im M2-Geschiebemergel zu urteilen - noch nicht wesentlich tiefer in den Untergrund gewirkt hat.
Ein weiteres Indiz für die relative Hochlage des Raumes Jasmund im Pleistozän liefert die Abtragung der Paläogen- und der Pleistozänsedimente bis zur Saale-Vereisung, während im Seegebiet östlich davon und in der Oderbucht Paläogensedimente mindestens bis zum Vorstoß des stauchenden M3-Eises erhalten geblieben waren. Über Rügen hinaus nach Norden waren sie ursprünglich bis ins südliche Schweden verbreitet, und dazwischen sind nördlich von Rügen im Seegebiet von Kriegers Flak paläogene Kalke unter dem Pleistozän in tieferer Position noch erhalten (LudWig 2001, ANJAR et al. 2010). Ferner lagern in SWRügen auf Campan-Kreide noch einige Meter Eozänsedimente (HAupt 1996). Während Glazialschollen paläogener Sedimente im Pleistozän von Südostrügen, auf der Insel Greifswalder Oie und in der südlichen Umrandung der Oderbucht zusammen mit Tertiärgeschieben häufig vorkommen (KNAUST 1995, Ludwig 1999) sind aus dem Pleistozän von Jasmund (und von Wittow) keine Tertiärschollen, nur Tertiärgeschiebe bekannt geworden.

Die relative Hochlage von Jasmund im Pleistozän geht weiter daraus hervor, dass unter der M1-Geschiebemergeldecke (Abb. 3), die dem Warthe-Eisvorstoß zugeordnet wird, höchstens sehr geringe Reste prä-warthezeitlichen Pleistozäns (Geschiebemergel) erhalten sind, die PANzIG (1991) anhand von Geschiebezählungen ausgeschieden hat. Der M1-Geschiebemergel könnte aber auch erst ins frühe Weichselglazial gehören, da in der hangenden I1-Folge Spuren der Eem-Warmzeit fehlen, und weil es in Mecklenburg-Vorpommern Hinweise auf eine Moräne gibt, die älter als das Brandenburger Stadium der Weichsel-Vereisung ist, ähnlich wie in Nordpolen (MüLLER 2004).

\subsubsection{Untergrundstrukturen und neotektonische Entwicklung im Raum Rügen}

Der Raum Rügen mit dem vor allem östlich angrenzenden Gebiet ist tektonisch durch ein engräumiges Bruchschollenmosaik geprägt, das im späten Paläozoikum angelegt und danach wiederholt aktiviert worden ist. In neotektonischer Zeit, seit dem frühen Oligozän, zeichnet es sich durch differenzierte Hebungen aus, oft in Fortsetzung älterer Hebungsbewegungen (SchlüTER et al. 1997, Ludwig 2001). Maßgebend für die strukturelle Entwicklung im Raum Rügen seit dem späten Paläozoikum ist das Zusammentreffen zweier tektonisch sehr aktiver Hauptstrukturzonen der europäischen Erdkruste: des Südwestrandes der Osteuropäischen Tafel (OET) mit der Tornquist-Sorgenfrei-Zone im NW (TSZ) und der dazu seitlich versetzten Tornquist-Teisseyre-Zone im SE (TTZ) mit der meridionalen Schwächezone mit Senkungscharakter, die ausgehend von Nordböhmen über das Zittauer Becken und die Täler von Neiße und Unterer Oder nördlich der Oderbucht auf die TTZ zuläuft (Ludwig 2001) (Abb. 19). Jasmund liegt im SW-Vorfeld beider neotektonisch aktiven Strukturen.

Während der Oberkreide hatte noch die Dänisch-Polnische Senke den Südwestrand der OET markiert. Seit der Wende ins frühe Tertiär wurde die Senkung in der Tafelrandzone von einer ausgeprägten Inversionstektonik abgelöst. In der TSZ führte die Inversion zur engräumig differenzierten Hebung von Leistenschollen (Schonen, Bornholm und nach SE darüber hinaus), in der seitlich ver- 


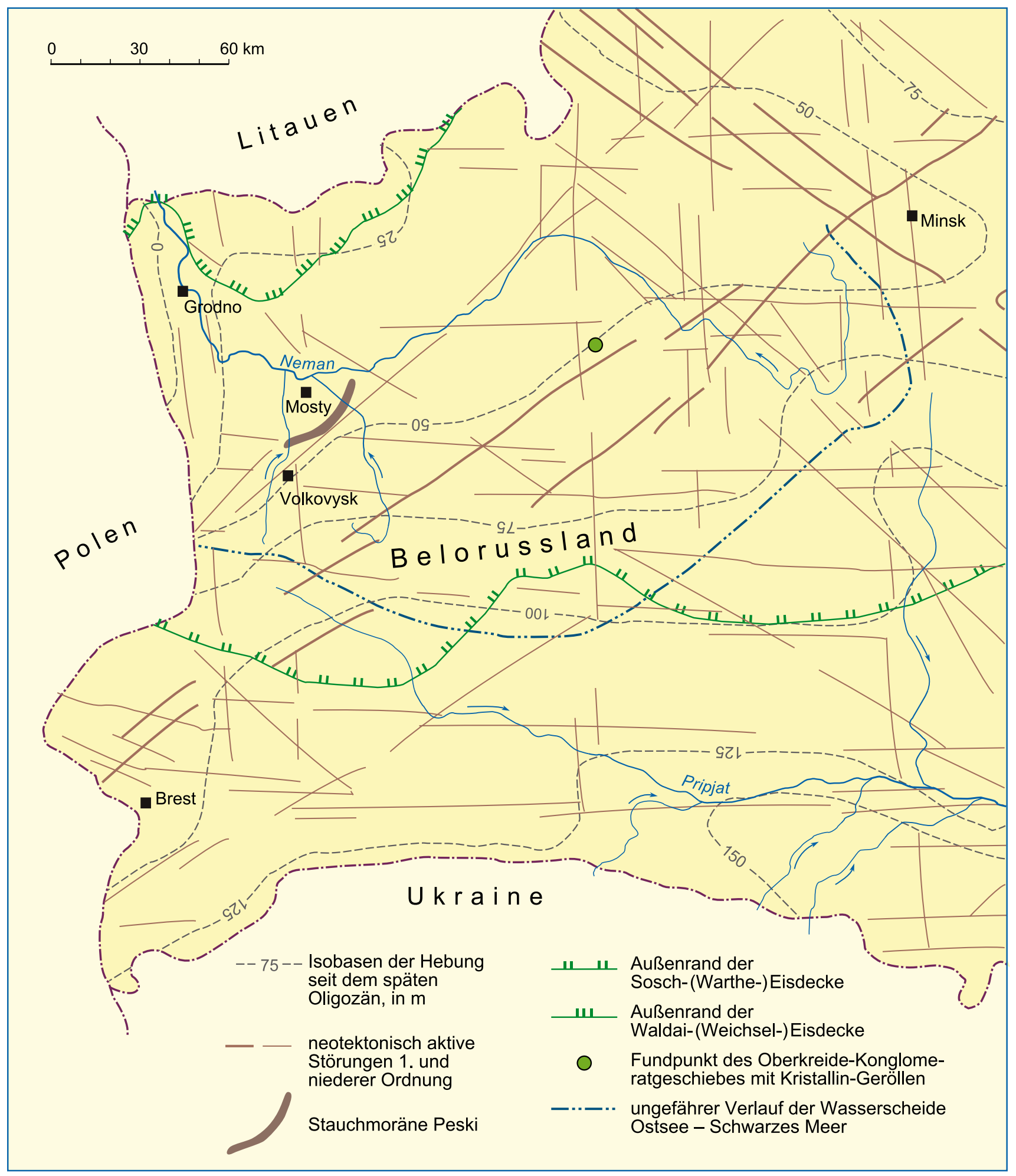

Abb. 17: Position der Stauchmoräne Peski in Beziehung zum geologischen Untergrund, Bruchstrukturen und neotektonische (+ glazialisostatische) Mobilität (nach LEVKOV \& KARABANOV 1996, Flüsse und Eisrandlagen ergänzt).

Fig. 17: Position of the Peski push moraine in relation to ruptures in the underground and neotectonic (+glacioisostatic) movements (from LEVKOV \& KARABANOV 1996, rivers and moraines complemented).

setzten TTZ zur Bildung einer weitspannigeren Wölbungsstruktur, die von Brüchen begrenzt und untergliedert wird (Pommerisch-Kujawischer Wall). Dabei ist die TTZ an der Adler-Kamien-Störung auf die Oberkreide in ihrem südwestlichen Vorfeld aufgeschoben (Thomas \& DeEks 1994, SCHLÜTER et al.1997) und die Basis der Oberkreide gegen W angehoben sowie leicht schräggestellt worden (Abb. 18).
Reste von Eozän auf Kreide des Campan in Halbgräben in SW-Rügen und von Oligozänsedimenten im Halbgraben von Möckow-Dargibell belegen postoligozäne Bruchbewegungen (Abb. 18 u. 19) und eine Reaktivierung des Vorpommern-Störungssystems (NNW-SSE). An diesem endet der Grimmener Wall im Osten (HAUPT 1996, Krauss \& MAYER 2004). Nach Norden schließt sich das Öresund-Störungs- 


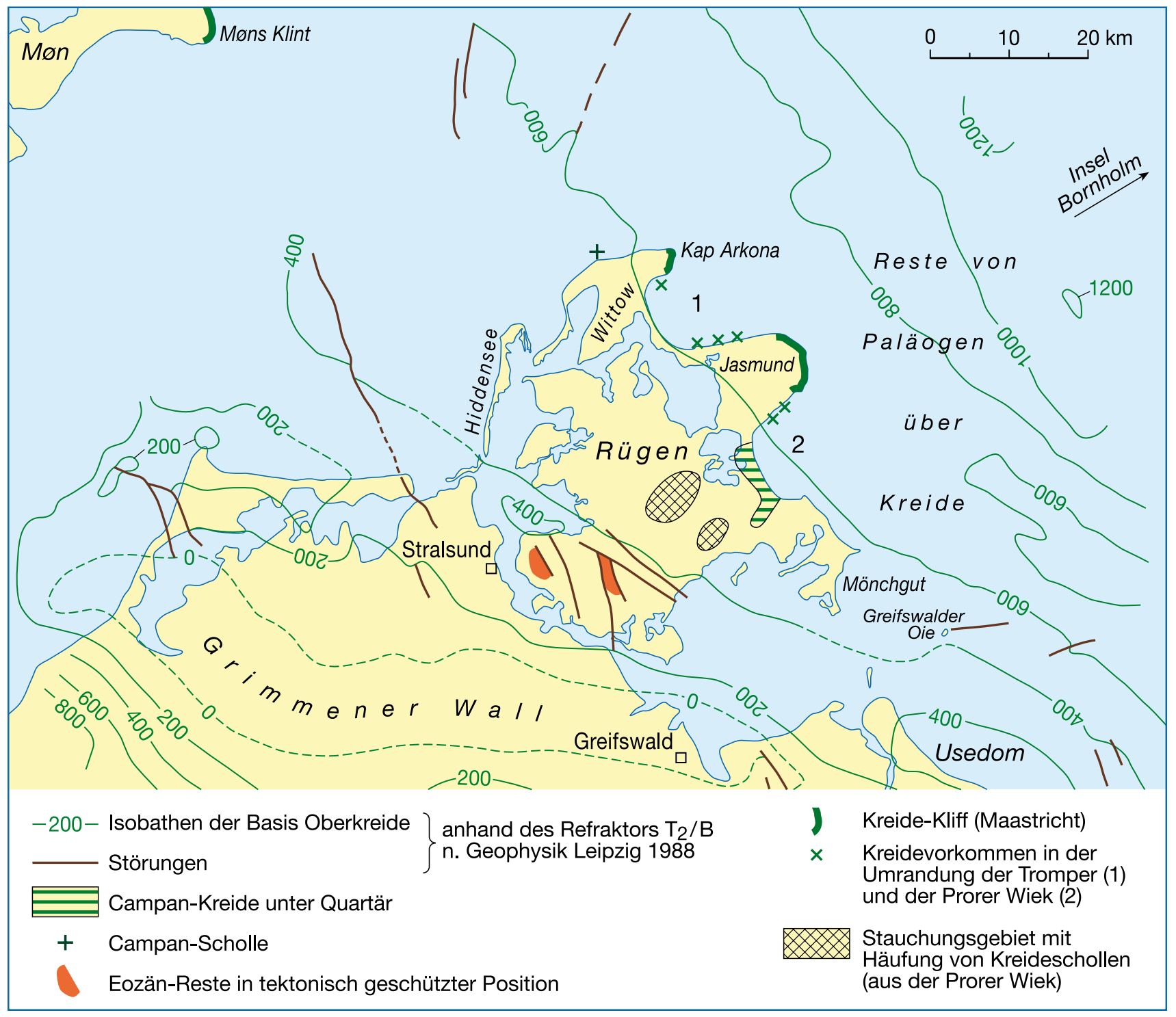

Abb. 18: Strukturelle Situation an der Basis der Oberkreide (zitiert nach KRAUSS 1993, Abb14, ergänzt).

Fig. 18: Structural situation at the base of the Upper Cretaceous beds (from KRAUSS 1993, Fig. 14, supplemented).

system an, das östlich an der Stauchmoräne Møn vorbei gegen Kopenhagen zieht und abgestuft die Kreide nach Westen angehoben hat.

Die Schichtlücken in der oberkretazisch-känozoischen Folge geben den vorwiegenden Hebungscharakter in der Region zu erkennen, im Gegensatz zur relativen Senkung im Bereich der meridionalen Zone, die von Süden an den SW-Rand der OET heranreicht (Abb. 19). In der Senkungszone sind in der Oderbucht Tertiärsedimente bis ins Pleistozän (und Holozän?) erhalten geblieben, ihr folgten der Odergletscher des Pommerschen Eisvorstoßes nach Süden und die Transgression des Cyprinentonmeeres östlich um Rügen herum bis in die Oderbucht (s. 4.2.1). Noch heute zeichnet eine Rinne im Ostseeboden, die dicht an Jasmund vorbei nach Norden läuft, den Lauf einer Ur -Oder nach. Die Anhebung der Oberkreideschichten gegen Rügen ist in Fortsetzung älterer Hebungstendenzen sicher nicht bruchlos geschehen. Die Brüche sind im Seegebiet östlich von Jasmund zu suchen. Dabei müssen keine spektakulären Bruchstufen entstanden sein, weil tektonische Impulse durch plastisch-fließende Deformationen der Kreide ge- dämpft werden können. Kleinere tektonische Versätze löst die Seismik aber nicht auf.

Die neotektonische Karte (GARETSKY et al. 2001) weist ebenfalls eine neotektonische Hebung für den Raum Rügen aus. Inwieweit pleistozäne Anteile darin enthalten sind, ist allerdings schwer abzuschätzen.

Auch die von STEINICH (1972) festgestellte prä-M1-zeitliche, engräumige, tektonisch interpretierte Zerblockung der später glazigen deformierten Oberkreide von Jasmund gibt keinen näheren Anhalt für die zeitliche Einordnung dieser Vorgänge. Der scharf wechselnde Anschnitt unterschiedlicher stratigraphischer Niveaus der Kreide (bis mehrere $10 \mathrm{~m}$ ) unter der Pleistozänbasis (M1-Geschiebemergeldecke) auf Jasmund und die daraus resultierende sehr engräumige Zerblockung könnten schon während der voraufgegangenen größeren Eisbelastungen geschaffen worden sein, indem oberste Kreideschichten damals bereits leicht gefaltet und abgeschliffen, aber nicht völlig abgeschert worden waren, so dass die Basis der Kreide davon unberührt geblieben ist.

Die Hochlage von Rügen und speziell von Jasmund im Vergleich zur Umgebung fügt sich der neotektonischen 


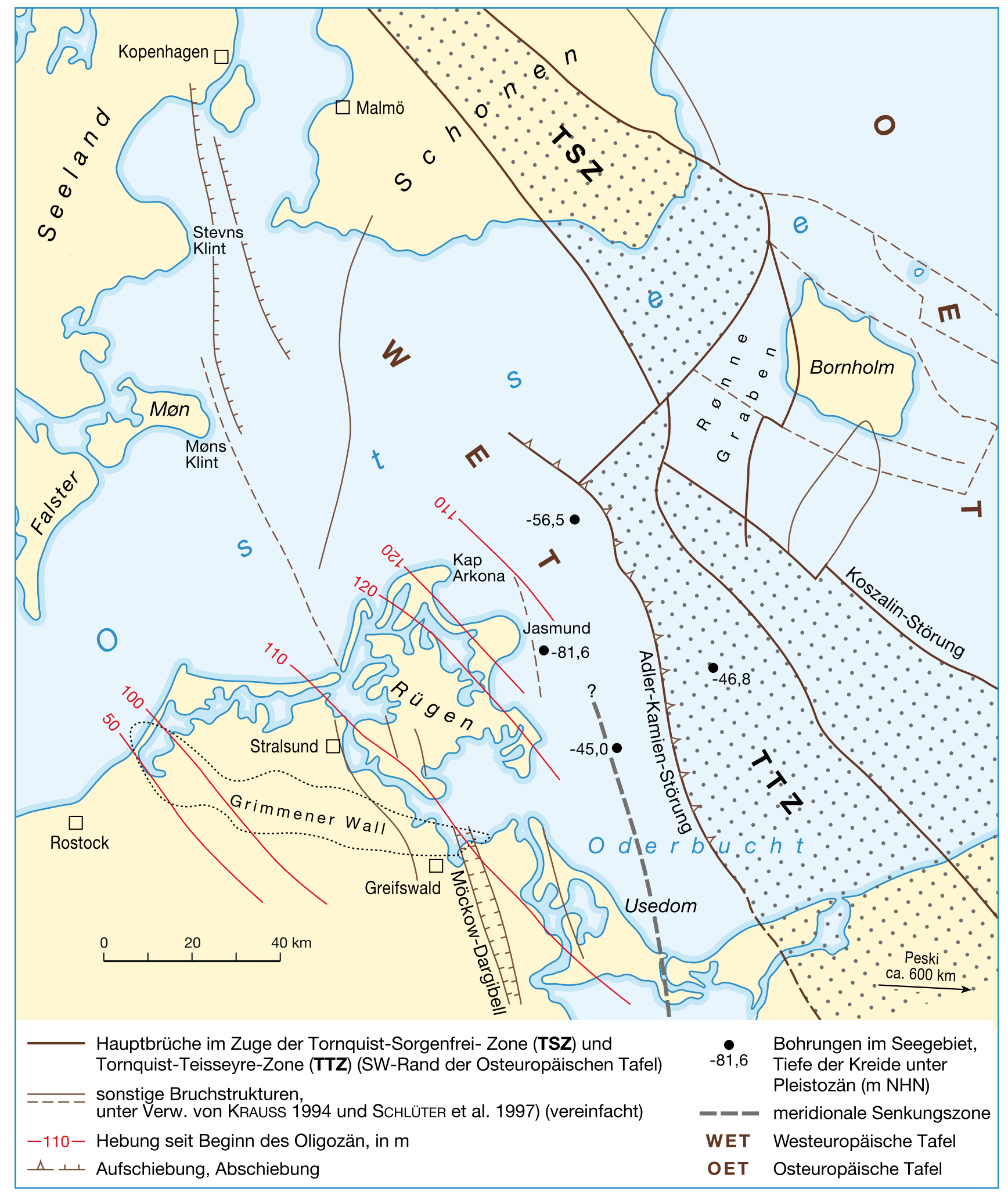

Abb. 19: Position der Stauchmoräne Jasmund in Beziehung zum geologischen Untergrund (Bruchstrukturen und neotektonische [+ glazialisostatische] Bewegungen). (Neotektonische Hebungen nach GARETSKY et al. map 1, 2001; Bohrungen nach SCHLÜTER et al. 1997).

Fig. 19: Position of the fasmund push moraine in relation to the geological underground (ruptures and neotectonic movements). (Neotectonic uplift after GARETSKY et al. map 1, 2001; bore holes after SCHLÜTER et al. 1997).

Entwicklung der Region zwanglos ein. In Fortsetzung älterer tektonischer Hebungstendenzen ist in neotektonischer Zeit der relativ erhöhte Kreidesockel der Insel geschaffen worden, der die Pleistozänauflage trägt (LuDwIG \& Schwab 1995). Die Abnahme der Hebungsintensität im Laufe des Tertiärs und die Kürze der Zeitspanne für das
Pleistozän lassen keine spektakulären reliefverstärkenden tektonischen Impulse erwarten, die bedeutende Angriffsflächen für das Eis geformt hätten. Die geologischen Befunde lassen solche auch nicht erkennen. Jedoch sind begrenzte vertikale Versätze und/oder Aufwölbungen nicht auszuschließen (Abtrag des Tertiärs und der älteren Pleis- 


\begin{tabular}{|c|c|c|c|c|}
\hline A. O. LUDWIG & \multicolumn{2}{|c|}{$\begin{array}{c}\text { Peski } \\
\text { (nach LeVkov 1980, Levkov \& KARABANov1996 } \\
\text { und mündliche Mitteilungen) }\end{array}$} & \multicolumn{2}{|c|}{$\begin{array}{c}\text { Jasmund } \\
\text { (STEINICH 1992a,b, GROTH 1961, 2003, LUDWIG 2005, 2006) }\end{array}$} \\
\hline Form & Weiträumiger Stauchmoränenbo & gen & $\begin{array}{l}\text { Schlingenförmige Stauchung zwischen } \\
\text { zwei Eisloben }\end{array}$ & \\
\hline Alter & Sosch-(Warthe) & & Weichsel & \\
\hline Bogenumfang & geologisch intensiv erkundet & ca. $30 \mathrm{~km}$ & $\begin{array}{ll}\text { Nordflügel } & \text { ohne an der Nord- und } \\
\text { Südflügel } & \text { Ostküste abradierte Teile }\end{array}$ & ca. $7,5 \mathrm{~km}$ \\
\hline $\begin{array}{l}\text { Breite quer } \\
\text { zum Bogen } \\
\text { (Streichen) }\end{array}$ & & $\begin{array}{r}3-5 \mathrm{~km} \\
\text { lokal } 8 \mathrm{~km}\end{array}$ & Nord- und Südflügel ähnlich & $3-4 \mathrm{~km}$ \\
\hline $\begin{array}{l}\text { Glazigen } \\
\text { gestörte } \\
\text { Schichtfolge }\end{array}$ & $\begin{array}{l}\text { Pleistozän } \\
\text { Paläo- und Neogen } \\
\text { Kreide; Campan }\end{array}$ & $\begin{array}{l}\text { bis } 50 \mathrm{~m} \\
\text { bis } 25 \mathrm{~m} \\
\text { bis } 50 \mathrm{~m}\end{array}$ & $\begin{array}{l}\text { Pleistozän } \\
\text { Kreide; Maastricht, stratigraphisch }\end{array}$ & $\begin{array}{l}\text { bis } 40 \mathrm{~m} \\
- \\
\text { bis } 90 \mathrm{~m}\end{array}$ \\
\hline $\begin{array}{l}\text { Schuppen, } \\
\text { Falten usw. }\end{array}$ & $\begin{array}{l}\text { Anzahl quer zum Streichen, } \\
\text { dazu einige kleine, } \\
\text { nicht näher untersucht }\end{array}$ & bis 20 & in Gruppen bis zu & 15 \\
\hline $\begin{array}{l}\text { Mächtigkeit der } \\
\text { zusammenge- } \\
\text { schobenen } \\
\text { Schichtfolge }\end{array}$ & & $80-130 m$ & sehr wechselnd & nax. $200 \mathrm{~m}$ \\
\hline $\begin{array}{l}\text { Lagerung } \\
\text { (Fallen) }\end{array}$ & $\begin{array}{l}\text { Außenseite des Bogens } \\
\text { Innenseite des Bogens }\end{array}$ & $\begin{array}{l}30-40^{\circ} \mathrm{N} \\
\text { bis } 90^{\circ}\end{array}$ & $\begin{array}{l}\text { äußere Erkundungsfelder, NW-Flügel } \\
\text { innere Erkundungsfelder, SW-Flügel } \\
\text { am Ostkliff schwach überkippt zum Eis }\end{array}$ & $\begin{array}{l}\text { um } 45^{\circ} \mathrm{NE} \\
\text { bis } 90^{\circ} \mathrm{SE} \\
\text { steil W }\end{array}$ \\
\hline Kreideanteil & ungefähr halbe Mächtigkeit bis e & twas mehr & mehr als die Hälfte & \\
\hline Aufragung & über die umgebende Landschaft & $15-20 \mathrm{~m}$ & über NHN (Ostseespiegel) & bis $161 \mathrm{~m}$ \\
\hline Kreidegruben & $\begin{array}{l}\text { Länge im Streichen } \\
\text { Breite bei steiler Lagerung } \\
\text { Tiefe }\end{array}$ & $\begin{array}{r}2-4 \mathrm{~km} \\
80-100 \mathrm{~m} \\
40 \mathrm{~m}\end{array}$ & einzeln & $\begin{array}{l}\text { bis } 1,5 \mathrm{~km} \\
20-70 \mathrm{~m} \\
\text { e bis } 40 \mathrm{~m}\end{array}$ \\
\hline
\end{tabular}

Abb. 20: Die Stauchmoräne Peski im Vergleich mit der Stauchmoräne fasmund.

Fig. 20: Push moraine Peski compared with push moraine Jasmund.

tozänsedimente). Die Hochlage des Kreidesockels von Rügen ist das Ergebnis längerer Entwicklung und nicht erst von tektonischen Impulsen im Intervall vor der Bildung der Stauchmoräne Jasmund. Im Verein mit den Hebungen der Halbinsel Schonen ist auch die Einschnürung der südlichen Ostsee zwischen diesen beiden Blöcken entstanden.

Wahrscheinlich haben auch die glazialisostatischen Abund Aufbewegungen der Erdkruste in der Region differenzierte Verschiebungen im Bruchschollenmosaik unter der Kreide ausgelöst und das Relief lokal zusätzlich verstärkt; denn schon die Befüllung von Talsperren führt zu messbaren isostatischen Effekten. Dabei konnten auch angesammelte tektonische Spannungen gelöst werden. In Nordschweden sind im Verlauf der glazialisostatischen Hebung im Anschluss an die Eisentlastung vertikale Versätze bis zu $10 \mathrm{~m}$ (extrem $20 \mathrm{~m}$ ) beobachtet worden (LAGERBÄcK 1990). Glazialisostatisch ausgelöste Versätze benachbarter Bruchschollen waren im Gebiet von Rügen und damit im Raum von Jasmund schon während der Vereisungen möglich, die der Bildung der Stauchmoräne vorausgegangen waren. Allerdings sind die glazialisostatischen Anteile von den neotektonischen Anteilen nicht zu trennen (ähnlich im Gebiet von Peski, s. 4.1). Auch glazialisostatisch entstandene Reliefzüge waren bis zur Stauchung den erosiven und exarativen Überformungen ausgesetzt.

Soweit aufragende Angriffsflächen für die glazigenen Deformationen eine Rolle gespielt haben, müssen sie nicht zwangsläufig auf akute reliefverstärkende tektonische Akte im Intervall vor der Stauchung zurückgeführt werden. Vielmehr können aus den tektonischen Vorlagen, die seit dem frühen Tertiär mindestens bis ins weichselzeitliche Pleistozän geschaffen worden waren, längerfristig die Hebungskerne erosiv und exarativ herausmodelliert, das heißt passiv morphologisch verstärkt worden sein; denn erst das Zusammenspiel der längerperiodisch gesteuerten tektonischen mit den kürzerperiodisch gesteuerten erosiv-exarativen Prozessen hat die Geländeformung in der Region vor der Stauchung bestimmt.

Die Hebungsgebiete sind ungeachtet ihrer tektonischen oder/und glazialisostatischen Entstehung während der vorausgegangenen Eisübergänge mindestens bis zur Ablagerung der M1-Geschiebemergeldecke (Warthe-Eisvorstoß?, s. 4.2.1) abgeschliffen worden, ohne dass in der Region eine Verebnung erreicht worden war. Zur Zeit des Cyprinen- 
tonmeeres müssen zwischen dem damals nicht überfluteten Jasmund und dem benachbarten Meeresboden Höhendifferenzen bis zu wenigen 10 Metern bestanden haben. So sind schon für die Zeit vor dem M3-Eisvorstoß Hohlformen im Bereich des Arkonabeckens und der Oderbucht vorauszusetzen, in denen sich größere Eismassen zum erneuten Vorstoß ansammeln und diese Hohlformen weiter ausarbeiten konnten. Die Hochlage dazwischen hat zur Teilung des Ostseegletschers in einen Eisstrom nördlich um Rügen herum und einen in der Oderbucht nach Süden abzweigenden Eisstrom beigetragen.

Da die früheren Eisübergänge über den Raum Jasmund ohne tiefergreifende Einwirkungen auf den Untergrund geblieben waren, obwohl sich eine relative Hochlage schon über längere Zeit entwickelt hatte, kann das endogen-exogene Wechselspiel die Voraussetzungen für die Bildung der Stauchmoräne und ihre Lokalisierung zunächst nur zum Teil geschaffen haben. Die Stauchung müssen weitere Faktoren begünstigt und ausgelöst haben.

\subsubsection{Die Stauchung als Funktion des Klimaverlaufs und seiner Folgeprozesse}

Der Vergleich der Stauchmoräne Jasmund mit der Stauchmoräne Peski bestätigt die Erfahrung, dass die Stauchung nicht vom gestauchten Gesteinsmaterial schlechthin abhängt, sondern von dessen bodenmechanischen Eigenschaften. Diese haben sich im Rhythmus der pleistozänen Klimaschwankungen geändert, mit zeitlichen Verzögerungen wie sie für den Eisauf- und -abbau (und weitere Folgeprozesse) zutreffen. Demzufolge werden umfangreiche glazigene Deformationen dann ausgelöst, wenn im Gefolge der klimatischen Entwicklung im Bereich der Eisstirn der dafür günstige bodenmechanische Zustand erreicht wird. Bei beiden Stauchmoränen fällt die Deformation in die Periode der generellen Wiedererwärmung nach der klimatischen Wende zur Wiedererwärmung im Laufe einer Kaltzeit (ähnlich beim Muskauer Faltenbogen, jedoch schon nach der maximalen Ausbreitung des Elster-Eises, s. Kupetz 1997).

Während des Anlaufs einer Vereisungsperiode bis zum Kälteoptimum hatte sich im Vorland vor der nahenden Eisdecke ein tiefgründiger Dauerfrostboden entwickelt, über den das Eis ohne bedeutende Einwirkungen hinweggeglitten war. Bereits unter der isolierenden Eisdecke, und verstärkt nach der Klimawende, haben der von unten und oben auftauende Dauerfrostboden und der Grad der Wassersättigung (Porenwasserdruck) der Schichten darunter sowie ihre Neigung zum Eis hin (ungünstige Drainageverhältnisse) gute bodenmechanische Voraussetzungen für die Stauchung geschaffen (Levkov 1980, Piotrowski o Windelberg 2003). Mit deren Erreichen war jeweils vor allem der Zeitpunkt der Stauchung bestimmt. In der südlichen Ostsee war dieser für die Bildung von Stauchmoränen günstige Zustand während der Schwundperiode des Weichseleises nach dem Brandenburger Stadium an mehreren Stellen erreicht und hat außer im Gebiet von Jasmund - nicht streng gleichzeitig - zur Bildung der Stauchmoränen der Inseln Hiddensee und Møn, am Kap Arkona (weitgehend zerstört), weiter nach Westen der Stoltera (westlich von Warnemünde), der Kühlung, der Insel Poel, an den Klützer Höveds, und am Ristinge Klint(Insel Langeland, Dänemark) geführt, um nur einige aus dem Küstengebiet zu nennen.

Die reliefverstärkenden, längerperiodischen endogenen (und glazialisostatisch modifizierende) Prozesse haben zwar für die glazigene Deformation günstige topographische Verhältnisse geschaffen und die Orte der Stauchungen mitbestimmt; für die Zeitpunkte der Stauchungen aber war die Entwicklung dafür günstiger bodenmechanischer Eigenschaften maßgebend, die vom kürzerperiodischen pleistozänen Klimagang und seinen Folgeprozessen (Aufund Abbau des Dauerfrostbodens und der Eisdecken, Glazialiso- und -eustasie) gesteuert worden ist. Erst das $\mathrm{Zu}$ sammentreffen dieser günstigen Voraussetzungen hat die glazigenen Deformationen größeren Stils in Gang gesetzt. Die endogen und erosiv-exarativ geformte topographische Vorlage war nicht erst kurz vor dem Andrängen des stauchenden Eises entstanden, das trifft nur auf die exogen gesteuerten günstigen bodenmechanischen Eigenschaften des Untergrunds zu.

\section{Vergleich beider Stauchmoränen und Folgerungen}

Der Hauptunterschied zwischen beiden Stauchmoränen zeigt sich in den Architekturen:

- Peski: ein regelmäßig entwickelter Dehnungsbogen vor der Stirn eines ausgedehnten Lobus des Inlandeises in einer weiten, flach ansteigenden Landschaft; unkomplizierte Bogenarchitektur.

- Jasmund: Stauchung in der Kerbe zwischen zwei Eisloben, die in stärker reliefiertes Gelände vorgestoßen sind; kompliziertere Anordnung der Strukturelemente, besonders im über die Umgebung höher herausgepressten Kern der Stauchmoräne; die Anlage als Kompressionsbogen zwischen den Flanken der beiden Eisloben mit Anbau zweier unvollständig entwickelter Dehnungsbögen im N und S erklärt die Diskrepanz zwischen Struktur und Morphologie am Ostkliff von Jasmund besser als das Modell einer spitzwinkligen Kerbstauchung.

- Ungeachtet der sehr unterschiedlichen Architektur der beiden Stauchmoränen gleichen sich die Formen und Dimensionen ihrer Strukturelemente weitgehend. Das bestätigt die Regel, dass der Stil und der Zeitpunkt der glazigenen Deformation maßgeblich von der Entwicklung der bodenmechanischen Eigenschaften der Schichten im Gefolge des Klimaablaufs bestimmt werden.

- In beide Stauchmoränen sind Oberkreideschichten (Schreibkreidefazies mit Flintlagen) in die Stauchung einbezogen.

- Beide Stauchmoränen sind vom stauchenden Eis überfahren, aber nicht eingeebnet worden.

- Beide Stauchmoränen unterscheiden sich im Alter, sie sind aber beide jeweils nach der maximalen Eisausbreitung einer Eiszeit entstanden, die Stauchmoräne Peski nach dem Maximum der Dnepr-(Saale) Vereisung, Sosch-Vorstoß, die Stauchmoräne Jasmund nach dem Maximum der WeichselVereisung (nach dem Brandenburg-Stadium), wahrscheinlich beim Pommerschen Eisvorstoß.

Diese Klimaabschnitte zur generellen Wiedererwärmung hin boten die günstigsten bodenmechanischen Bedingungen für glazigene Deformationen großen Stils. Das 
wird durch bedeutende weitere Stauchmoränen dieser Perioden im südwestlichen Ostseegebiet und in Westbelorussland unterstrichen.

- Die Entwicklung der bodenmechanischen Eigenschaften der Schichtpakete im jeweiligen Eisrandgebiet (vor und unter dem Eis) folgt den extremen pleistozänen Klimaschwankungen. Sie hat die glazigenen Deformationen maßgeblicher beeinflusst als das von den topographischen Verhältnissen ausgegangen ist.

- Beide Stauchmoränen stehen in deutlicher Beziehung zum tektonischen Strukturmuster und den langfristig vorherrschenden tektonischen Hebungstendenzen in ihrer Region, die mindestens bis ins Pleistozän angedauert haben.

- Diese Gemeinsamkeiten in den Beziehungen zu den strukturellen Gegebenheiten des Untergrunds und zu den neotektonischen Hebungstendenzen bestehen ungeachtet der erheblich tieferen Lage des Grundgebirges im Raum Rügen im Vergleich zur geringen bei Peski und ungeachtet der sehr unterschiedlichen Architekturen der beiden Stauchmoränen.

- Beide Stauchmoränen (und andere) sind das Ergebnis des komplizierten räumlichen und zeitlichen Zusammenwirkens längerperiodisch gesteuerter endogener Vertikalbewegungen, die günstige topographische Ansätze für die Stauchungen geschaffen haben, und kürzerperiodischer exogener Prozesse, die letztlich von den extremen Klimaschwankungen während des Pleistozän gesteuert worden sind.

\section{Dank}

Den Herren Prof. Dr. E.A. Levkov† und Dr. A.K. Karabanov, beide Institut für geologische Wissenschaften der Akademie der Wissenschaften Belorusslands in Minsk, danke ich für ihre sachkundigen Führungen durch die großartigen Aufschlüsse bei Peski, den beiden Gutachtern für ihre Anregungen und ergänzenden Literaturhinweise. Außerdem gilt mein Dank Herrn Prof. Dr. A. Brauer (Deutsches GeoForschungsZentrum Potsdam) für die Gewährung zeichentechnischer Unterstützung, Frau M. Dziggel und Herrn A. Hendrich für die druckreife Gestaltung der Abbildungen.

\section{Literatur/References}

Anjar, J., Larsen, N. K., Björck, S., Adrielsson, L.も Filipsson, H. L. (2010): MIS 3 marine and lacustrine sediments at Kriegers Flak, southeastern Baltic Sea. - Boreas, 39: 360-366.

BERTHELSEN, A. (1979): Recumbent folds and boudinage structures formed by subglacial shear: An example of gravity tectonics. - Geologie en Mijnbouw, 58(2): 253-260.

BRINkMANN, R. (1953): Über die diluvialen Störungen auf Rügen. - Geologische Rundschau, 41: 231-241.

CARLÉ, W. (1938): Das innere Gefüge der Stauch-Endmoränen und seine Bedeutung für die Gliederung des Altmoränengebiets. - Geologische Rundschau,29: 27-51.

GARETSKy, G. et al.(eds.)(2001): Neogeodynamics of the Baltic sea depression and adjacent areas. IGCP project 346. - Brandenburgische Geowissenschaftliche Beiträge, 8: 5-12 und Map 1 West sheet.

GrIPP, K. (1947): Jasmund und Moen eine glazialmorphologische Untersuchung. - Zeitschrift für Erdkunde, 1: 175-182.

GRIPP, K. (1955): Eisbedingte Lagerungsstörungen. - Geologische Rundschau, 43: 39-45.

Groth, K. (1961): Die Lagerungsformen und -verhältnisse der Kreideschollen im Kreidekalkvorkommen Wittenfelde auf Jasmund (Rügen). - Geologie, 10: 803-810.
Groth, K. (2003): Zur glazitektonischen Entwicklung der Stauchmoräne Jasmund/Rügen. - Schriftenreihe des Landesamtes für Umwelt, Naturschutz und Geologie Mecklenburg-Vorpommern: 39-49.

HAupt, J. (1996): Geologische Karte von Mecklenburg-Vorpommern, Verbreitung der unter dem Quartär anstehenden Bildungen mit Tiefenlage der Quartärbasis, 1:500 000. - Geologisches Landesamt Mecklenburg-Vorpommern, 1. Aufl.

HoumARK-NiELSEN, M. (1994): Late Pleistocene stratigraphy, glaciation chronology and Middle Weichselian environmental history from Klintholm, Møn, Denmark. - Bulletin of the Geological Society of Denmark, 41: 181-202.

Katzung, G. (2004): 4.5.8 Kliff der Greifswalder Oie. - In: Katzung,G. (Hrsg.): Geologie von Mecklenburg-Vorpommern: 325-327, Stuttgart (E. Schweizerbart).

KeIlHack, K. (1914): Die Lagerungsverhältnisse des Diluviums in der Steilküste von Jasmund auf Rügen. - Jahrbuch der Preußischen Geologischen Landesanstalt, 33(I): 114-158.

KNAust, D. (1995): Die geologische Entwicklung der Ostseeinsel Greifswalder Oie. - Terra Nostra, 6: 47-69.

Köster, R. (1960): Wulfener Berg und Ristinge Bank, ein glazialtektonischer Vergleich. - Zeitschrift der deutschen geologischen Gesellschaft, 112: 515-532.

Krauss, M. (1993): Zur stofflichen und strukturellen Entwicklung und Situation im Untergrund der Insel Rügen. - In: Rügen, Bornholm, Exkursionsführer der Gesellschaft für Geowissenschaften e.V. Berlin, 05.-10.10.1993 auf Rügen und Bornholm: 15-32.

Krauss, M \& Mayer, P. (2004): Das Vorpommern Störungssystem und seine regionale Einordnung zur Transeuropäischen Störung. - Zeitschrift für geologische Wissenschaften 32: 227-246.

KupETZ, M. (1997): Geologischer Bau und Genese der Stauchmoräne Muskauer Faltenbogen. - Brandenburger Geowissenschaftliche Beiträge 4(2): 1-20.

LAGERBÄCK, R. (1990): Late Quaternary faulting and paleoseismicity in northern Fennoscandia, with particular reference to the Lansjärv area, northern Sweden. - Geologiska Föreningens i Stockholm Förhandlingar, 112: 333-354.

Levkov, E. A. (1980): Glazitektonika. - 279 S.; Minsk (Nauka i technika) (russ.).

Levkov, E. A. \& Karabanov, A. K. (1996): Neogeodynamics and Glacitectonics of Belarus (guide book) - 6th International Meeting of the IGCP Project 346 „Neogeodynamica Baltica“ Minsk 1996: 9 p.

Ludwig, A. O. (1954/55): Eistektonik und echte Tektonik in Ost-Rügen (Jasmund). - Wissenschaftliche Zeitschrift der Universität Greifswald, Math.-Nat. R. IV: 251-288.

Ludwig, A.O. (1964): Untersuchung des Pleistozäns der Ostseeküste von der Lübecker Bucht bis Rügen. - Geologie, Beiheft, 42: $143 \mathrm{~S}$.

Ludwig, A. O. (1999): Glazialschollen am Westrand der Oder-Bucht (südliche Ostsee). - Greifswalder Geowissenschaftliche Beiträge, 6: 419-427.

Ludwig, A.O. (2001): Die neotektonische Ausgestaltung des südlichen Ostseeraumes. - Zeitschrift für geologische Wissenschaften, 29: 149-167.

Ludwig, A. O. (2004): Zur Bildung der Stauchmoräne Dornbusch/Insel Hiddensee. - Zeitschrift für geologische Wissenschaften, 32: 255-269.

Ludwig, A. O. (2005): Zur Interpretation des Kliffanschnitts östlich von Glowe/Insel Rügen (Ostsee). - Zeitschrift für geologische Wissenschaften, 33: 263-272.

Ludwig, A. O. (2006): Cyprinenton und I1-Folge im Pleistozän von Nordost-Rügen und der Insel Hiddensee (südwestliche Ostsee). -Zeitschrift für geologische Wissenschaften, 34(6): 349-377.

Ludwig, A. O. \& Levkov, E. A. (2001): Ein Konglomeratgeschiebe als Hinweis auf differenzierte Schollenbewegungen in der westlichen Osteuropäischen Tafel während der Oberkreide. - Zeitschrift für geologische Wissenschaften, 17: 935-946.

Ludwig, A. O. \& SchwAB, G. (1995): Neogeodynamica Baltica - ein internationales Kartenprojekt (IGCP-Projekt Nr. 346). - Brandenburgische Geowissenschaftliche Beiträge, 2: 47-57.

MüLLER, U. (2004): 4.2 Jung-Pleistozän - Eem-Warmzeit bis WeichselHochglazial. - In: KATZUNG, G. (Hrsg.): Geologie von MecklenburgVorpommern: 234-242, Stuttgart (E. Schweizerbart).

Obst, K. \& Ansorge, J. (2010): Exkursion G - Die Greifswalder Oie - ein einzigartiges Vorkommen von präpleistozänen Schollen und Geschieben in einer hochdeformierten quartären Abfolge. - In: LAMPE, G. \& LORENZ, S. (eds.): Eiszeitlandschaften in Mecklenburg-Vorpommern 132-158; Greifswald (Geozon Science Media). 
PAnZIG, W.-A. (1991): Zu den Tills auf Nordostrügen. - Zeitschrift für geologische Wissenschaften, 19: 331-346.

Pedersen, S. A, S. (2000): Superimposed deformation in glaciotectonics. Bulletin of the Geological Society of Denmark, 46: 125-144.

Piotrowski, J. \& Windelberg, S. (2003): Glazialtektonik und weichselzeitliche Ablagerung in Zentral-Fünen Dänemark. - Eiszeitalter und Gegenwart, 53: 39-54

Richter, W., SCHNeIDER, H. ¿ WAGER, R. (1951): Die saalezeitliche Stauchmoräne von Itterbeck-Uelsen (Grafschaft Bentheim). - Zeitschrift der deutschen geologischen Gesellschaft, 102(I): 60.75 .

RüHBERG, N. (1969): Die Geologie der pleistozänen Schichtenfolge am Westkliff von Poel. - Geologie, 18: 626-637.

Scharf, W. (1933): Das norddeutsche Diluvium in eistektonischer Betrachtung. - Jahrbuch der Preußischen Geologischen Landesanstalt, 53: $828-850$
SchlÜter, H.-U., Best, G., JÜrgens, U. \& Binot, F.(1997): Interpretation reflexionsseismischer Profile zwischen baltischer Kontinentalplatte und kaledonischem Becken in der südlichen Ostsee - erste Ergebnisse. - Zeitschrift der deutschen geologischen Gesellschaft, 148: $1-32$.

Steinich, G. (1972): Endogene Tektonik in den Unter-Maastricht-Vorkommen auf Jasmund (Rügen). - Geologie, Beiheft 71/72: $207 \mathrm{~S}$.

Steinich, G. (1992): Die stratigraphische Einordnung der Rügen-Warmzeit - Zeitschrift für geologische Wissenschaften, 20: 125-154.

Struckmann, C. (1879): Briefliche Mitteilung an W. Dames. - Zeitschrift der deutschen geologischen Gesellschaft, 31: 788.

Thomas, S. A. \& Deeks, N. R. (1994): Seismic evidence for inversion tectonics in the strike-slip regime of the Tornquist zone, Southern Baltic Sea. - Zeitschrift für geologische Wissenschaften, 22: 33-45. 